\title{
Antioxidant and Antiulcerogenic Activity of the Dry Extract of Pods of Libidibia ferrea Mart. ex Tul. (Fabaceae)
}

\author{
Lady D. K. T. Prazeres $\mathbb{D}^{1},{ }^{1}$ Ticiana P. Aragão, ${ }^{2}$ Samara A. Brito, ${ }^{3}$ Cynthia L. F. Almeida ${ }^{4},^{4}$ \\ Amanda D. Silva, ${ }^{1}$ Mirella M. F. de Paula, ${ }^{5}$ Juliane S. Farias, ${ }^{5}$ Leucio D. Vieira, ${ }^{5}$ \\ Bolívar P. G. L. Damasceno $\mathbb{D}^{6},{ }^{6}$ Larissa A. Rolim $\mathbb{D}^{7}{ }^{7}$ Bruno O. Veras ${ }^{D},{ }^{8}$ Ismael G. Rocha, ${ }^{9}$ \\ Jacinto C. Silva Neto ${ }^{D},{ }^{9}$ Milena L. F. Bittencourt, ${ }^{10}$ Rita de Cássia R. Gonçalves, ${ }^{10}$ \\ Rodrigo R. Kitagawa $\mathbb{D}^{10}$ and Almir G. Wanderley $\mathbb{D}^{1,5}$
}

${ }^{1}$ Department of Pharmaceutical Sciences, Universidade Federal de Pernambuco, Recife 50740-521, Brazil

${ }^{2}$ Department of Nutrition, Universidade de Pernambuco, Petrolina 56328-903, Brazil

${ }^{3}$ Santa Maria College, Cajazeiras 58900-000, Brazil

${ }^{4}$ Collegiate of Nursing, Universidade Federal do Vale do São Francisco, Petrolina 56304-205, Brazil

${ }^{5}$ Department of Physiology and Pharmacology, Universidade Federal de Pernambuco, Recife 50670-901, Brazil

${ }^{6}$ Department of Pharmacy, Universidade Estadual da Paraíba, Campina Grande 58429-600, Brazil

${ }^{7}$ Drugs, Medicines and Food Analysis Center, Universidade Federal do Vale do São Francisco, Petrolina 56304-917, Brazil

${ }^{8}$ Department of Tropical Medicine, Universidade Federal de Pernambuco, Recife 50670-901, Brazil

${ }^{9}$ Department of Histology and Embryology, Universidade Federal de Pernambuco, Recife 50670-420, Brazil

${ }^{10}$ Graduate Program in Pharmaceutical Sciences, Universidade Federal do Espírito Santo, Vitória 29047-105, Brazil

Correspondence should be addressed to Almir G. Wanderley; almir.wanderley@ufpe.br

Received 6 June 2019; Accepted 18 September 2019; Published 20 November 2019

Academic Editor: Pedro Mena

Copyright (c) 2019 Lady D. K. T. Prazeres et al. This is an open access article distributed under the Creative Commons Attribution License, which permits unrestricted use, distribution, and reproduction in any medium, provided the original work is properly cited.

\footnotetext{
Ethnomedicinal studies in the Amazon community and in the Northeast region of Brazil highlight the use of Libidibia ferrea fruits for the treatment of gastric problems. However, there are no data in the literature of this pharmacological activity. Thus, the aim of this paper is to provide a scientific basis for the use of the dry extract of L. ferrea pods (DELfp) for the treatment of peptic ulcers. Phytochemical characterization was performed by HPLC/MS. In vitro antioxidant activity was assessed using DPPH, ABTS, phosphomolybdenum, and superoxide radical scavenging activity. The gastroprotective activity, the ability to stimulate mucus production, the antisecretory activity, and the influence of -SH and NO compounds on the antiulcerogenic activity of DELfp were evaluated. The healing activity was determined by the acetic acid-induced chronic ulcer model. Anti-Helicobacter pylori activity was investigated. HPLC/MS results identified the presence of phenolic compounds, gallic acid and ellagic acid, in DELfp. The extract showed antioxidant activity in vitro. In ulcers induced by absolute ethanol and acidified ethanol, the $\mathrm{ED}_{50}$ values of DELfp were 113 and $185.7 \mathrm{mg} / \mathrm{kg}$, respectively. DELfp $(100,200$, and $400 \mathrm{mg} / \mathrm{kg})$ inhibited indomethacin-induced lesions by $66.7,69.6$, and $65.8 \%$, respectively. DELfp $(200 \mathrm{mg} / \mathrm{kg})$ reduced gastric secretion and $\mathrm{H}^{+}$concentration in the gastric contents and showed to be independent of nitric oxide (NO) and dependent on sulfhydryl (-SH) compounds in the protection of the gastric mucosa. In the chronic ulcer model, DELfp reduced the area of the gastric lesion. DELfp also showed anti-H. pylori activity. In conclusion, DELfp showed antioxidant, gastroprotective, healing, and antiulcerogenic activities. The mechanism of these actions seems to be mediated by different pathways and involves the reduction of gastric secretion and $\mathrm{H}^{+}$concentration, dependence on sulfhydryl compounds, and anti-H. pylori activity. All these actions support the medicinal use of this species in the management of peptic ulcers.
} 


\section{Introduction}

Peptic ulcer (PU) is a term used to refer to an acid-peptic lesion of the gastrointestinal tract resulting in rupture of the mucosa and submucosa [1]. Ulcerative lesions occur due to an imbalance between the cytoprotective factors of the mucosa, such as the mucus-bicarbonate barrier and the presence of prostaglandins, and aggressive factors, among them reactive oxygen species (ROS) and hydrochloric acid $[2,3]$. It is estimated that 10 to $20 \%$ of PU cases are associated with comorbidities such as hemorrhages, obstructions, and perforations, with a mortality rate ranging from 10 to $40 \%$, with 2 to $14 \%$ of these mortality cases due to perforation [4-8]. Given this scenario, the scientific community has been continually challenged to contribute research to this area [2].

Several behavioral factors culminate in the development of PUs. They include inadequate eating habits, alcohol and tobacco consumption, stress, and the inadvertent use of nonsteroidal anti-inflammatory drugs (NSAIDs) [9]. In these situations, the defense mechanisms of the gastric mucosa, such as mucus and bicarbonate secretion, acid-base balance, endogenous sulfhydryl groups, and epidermal growth factor $[9,10]$, are insufficient to maintain tissue homeostasis, favoring the development of lesions.

Oxidative stress increases the formation of ROS such as superoxide anion $\left(\mathrm{O}_{2}^{-}\right)$, hydroxyl radical $\left(\mathrm{OH}^{-}\right)$, and hydrogen peroxide $\left(\mathrm{H}_{2} \mathrm{O}_{2}\right)$ [11]. Excess of ROS harms cellular proteins [12] and disrupts the gastrointestinal tract barrier, increasing tissue permeability, which contributes to inflammation. ROS also cause inflammation by stimulating polymorphonuclear leukocytes, enhancing tissue damage [13].

PU therapy evolved with the advent of gastric acid secretion inhibitors, antihistamines $\left(\mathrm{H}_{2}\right)$, and proton pump inhibitors [14]. Despite the advances, these pharmacological classes have adverse effects. Antihistamines may cause arrhythmia, gynaecomastia, and hematological alterations [15], and treatment with proton pump inhibitors may provoke hyperplasia of the parietal cells of the gastric glands [16].

In addition to adverse effects, other factors such as the nonresponsiveness to pharmacological treatment presented by some individuals should be considered [17], as well as the gastric harm and increased risk of complications such as bleeding and gastric or duodenal perforation in the elderly associated with the use of acetylsalicylic acid (AAS), a nonselective inhibitor of the cyclooxygenase- 2 enzyme, often used in the prophylaxis of cardiovascular diseases [18, 19].

Warren and Marshall [20] first described, in 1983, Helicobacter pylori as the etiologic factor of peptic ulcer. Despite the numerous studies, the survival of these bacteria in the acidic $\mathrm{pH}$ of the gastric lumen is still uncertain. However, bacterial growth in intimate contact with the epithelium, presumably near the neutral end of this gradient, favors bacterial existence due to protection of the overlying mucus $[20,21]$. About $90 \%$ of patients with chronic gastric lesions are infected with $H$. pylori. Alam et al. [22] and Khulusi et al. [23] showed an association between the concentration of these bacteria and the severity scores of the lesions.
Libidibia ferrea (Mart. ex Tul.) L. P. Queiroz var. ferrea, previously classified as Caesalpinia ferrea Mart. ex. Tul. var. ferrea, belongs to the Fabaceae family. It is popularly known as "pau-ferro" or "jucá" $[24,25]$ and is well represented in the semiarid regions of North and Northeast Brazil [26].

Ethnopharmacological studies in Amazonian communities in Brazil reported the use of C. ferrea in the form of tea and syrup and the infusion of the fruits for control of gastric problems [27].

Several biological activities of $L$. ferrea have been scientifically proven, including anti-inflammatory [28, 29], analgesic [28, 30], antibacterial [27], antihypertensive [31], and antidiabetic [26] activities. Guerra et al. [32] associated the activity of this species against lineages of colorectal cancer cells to the increase in glutathione (GSH) levels and reduction of lipid peroxidation.

Various studies with $L$. ferrea have shown the presence of bioactive compounds with antioxidant activity, important for the treatment of several diseases. Considering the use of this species in ethnomedicine, the lack of information in the literature, and the need to propose a therapeutic tool that may help in the treatment of PUs, this study investigated the antioxidant and antiulcerogenic activities of the pods, the renewable part of the plant, of L. ferrea.

\section{Materials and Methods}

2.1. Plant Material and Extract Preparation. Libidibia ferrea pods were collected in the municipality of Barbalha, Ceará, Brazil $\left(7^{\circ} 18^{\prime} 40^{\prime \prime} \mathrm{S}, 39^{\circ} 18^{\prime} 15^{\prime \prime} \mathrm{W}\right)$. A representative sample of the species was deposited in the Herbarium of the Agronomic Institute (IPA) under accession number 90603. The pods were dried at room temperature for $72 \mathrm{~h}$ and then ground in a knife mill (Wyllie Macro-TE 650). The plant material $(100 \mathrm{~g})$ was subjected to cold maceration with $40 \%$ hydroalcoholic solvent for 3 days. After this procedure, the extract was filtered and the solvent completely removed with the aid of a spray dryer (MSD 0.5, LabMaq, Ribeirão Preto, Brazil). The parameters used were as follows: drying air flow, $4.5 \mathrm{~m}^{3} / \mathrm{min}$; outlet temperature, $95^{\circ} \mathrm{C}$; compressed air flow rate, $40 \mathrm{~L} / \mathrm{min}$; and peristaltic pump, $0.5 \mathrm{~L} / \mathrm{h}$. The dry extract of $L$. ferrea pods (DELfp) presented a yield of $18.9 \%(w / w)$. For the in vivo experiments, the extract was diluted in distilled water at the moment of use.

\subsection{Phytochemical Study}

2.2.1. High-Performance Liquid Chromatography (HPLC$M S)$. The dry extract of $L$. ferrea pods was subjected to high-performance liquid chromatography coupled to mass spectrometry (LC-MS) using an octadecylsilane $(250 \times 4.6 \mathrm{~mm}, 5 \mu \mathrm{m}$, Luna C18, Phenomenex $)$ column. The stationary phase and mobile phase were composed of 2 solvents: A-ultrapure water containing $0.1 \%$ formic acid and $\mathrm{B}-$ methanol containing $0.1 \%$ formic acid (HPLC grade) at a flow rate of $1.0 \mathrm{~mL} / \mathrm{min}$ under the following gradient conditions: $95 \%$ to $5 \% \mathrm{~A}(0-60 \mathrm{~min}), 5 \%$ to $0 \% \mathrm{~A}$ (60-70 $\mathrm{min})$, and $0 \%$ to $95 \% \mathrm{~A}(70-90 \mathrm{~min})$. The stationary phase was maintained at $30^{\circ} \mathrm{C}$, and the volume injected was 
$20 \mu \mathrm{L}$ for the sample $(1 \mathrm{mg} / \mathrm{mL})$ monitored at 190 to $400 \mathrm{~nm}$ and 50 to $1000 \mathrm{~m} / z$. The analysis used LC-20 (Shimadzu, Kyoto, Japan) equipped with the quaternary bomb system model LC-20ADVP, degasser model DGU20A, PDA detector model SPD-20AVP, oven model CTO-20ASVP, automatic injector model SIL-20ADVP, and SCL-20AVP system controller coupled to an ESI-IT mass spectrometer (Bruker Daltonics, Billerica, MA, USA), equipped with an electrospray ionization source operating in the analyzer mode and by positive ion trap. The following mass spectrometer parameters were used: capillary voltage, $3.5 \mathrm{kV}$; desolvation temperature, $320^{\circ} \mathrm{C}$; gas flow, $10 \mathrm{~L} / \mathrm{min}$; and pressure, $60 \mathrm{PSI}$, using nitrogen as drying and misting gas.

\subsection{Quantification of Secondary Metabolites in DELfp}

2.3.1. Determination of Total Phenol Content. The total phenol content (TPC) of DELfp was determined using the Folin-Ciocalteu (FC) reagent, as described by Li et al. [33]. Gallic acid (GA) at concentrations of 31.25, 62.5, 125.0, 250.0, 500.0, and $1000 \mu \mathrm{g} / \mathrm{mL}$ was used to obtain the standard calibration curve (in triplicate). The results were expressed as mg equivalents of AG/g extract (mg EAG/g).

2.3.2. Determination of Flavonoid Content. The flavonoid content of DELfp was determined according to Woisky and Salatino [34]. A $0.5 \mathrm{~mL}$ aliquot of the $0.5 \mathrm{~mL}$ extract was added to $0.5 \mathrm{~mL}$ of $2 \% \mathrm{AlCl}_{3}(w / v)$ solution prepared in methanol. After 30 minutes of incubation at room temperature, protected against light, the absorbance at $420 \mathrm{~nm}$ was measured. Quercetin (Q) at the concentrations of 31.25, $62.5,125.0,250.0,500.0$, and $1000 \mu \mathrm{g} / \mathrm{mL}$ was used to obtain the standard calibration curve (in triplicate). Total flavonoid content was expressed as mg quercetin equivalents/g extract (mg EQ/g).

\subsection{In Vitro Antioxidant Activity of DELfp}

2.4.1. ABTS (2',2-Azino-bis (3-ethylbenzothiazoline-6sulfonate)) Radical Scavenging Activity. The ABTS scavenging activity was performed according to Uchôa et al. [35], using Trolox as a standard. All experiments were performed in triplicate. The inhibition percentage $(I \%)$ was calculated considering Equation (1), where $A_{c}$ is the absorbance of the control and $A_{\mathrm{s}}$ is the absorbance in the presence of the extract. The concentration required to eliminate $50 \%$ of ABTS radicals $\left(\mathrm{IC}_{50}\right)$ was calculated.

$$
I \%=\left[\frac{A_{\mathrm{c}}-A_{\mathrm{s}}}{A_{\mathrm{c}}}\right] \times 100 .
$$

2.4.2. DPPH (2,2-Diphenyl-1-picrylhydrazyl) Radical Scavenging Activity. Free radical scavenging activity was measured by means of hydrogen donation using the stable radical DPPH, using Trolox as a standard [36]. All experiments were performed in triplicate. The inhibition percentage $(I \%)$ was calculated considering Equation (2), where $A_{\mathrm{c}}$ is the absorbance of the control and $A_{\mathrm{s}}$ is the absorbance in the presence of the extract. The concentration required to eliminate $50 \%$ of $\mathrm{DPPH}$ free radicals $\left(\mathrm{IC}_{50}\right)$ was calculated.

$$
I \%=\left[\frac{A_{\mathrm{c}}-A_{\mathrm{s}}}{A_{\mathrm{c}}}\right] \times 100 .
$$

2.4.3. Total Antioxidant Activity (TAA). Total antioxidant activity (TAA) was performed according to the Prieto methodology [37], based on the reduction of molybdenum (VI) to molybdenum $(\mathrm{V})$, in the presence of antioxidants in acid $\mathrm{pH}$. All experiments were performed in triplicate. The TAA of the samples was expressed in relation to ascorbic acid (AA, 0$1000 \mu \mathrm{g} / \mathrm{mL}$ ) used as a standard, whose reference antioxidant activity was considered equal to $100 \%$, using Equation (3), where $A_{\mathrm{s}}$ is the absorbance of the sample, $A_{\mathrm{c}}$ is the absorbance of the control (blank: without extract), and $A_{\mathrm{aa}}$ is the absorbance of ascorbic acid. The concentration required for $50 \%$ of activity $\left(\mathrm{IC}_{50}\right)$ was calculated.

$$
\% \mathrm{TAA}=\frac{\left(A_{\mathrm{s}}-A_{\mathrm{c}}\right) \times 100}{A_{\mathrm{aa}}-A_{\mathrm{c}}} .
$$

2.4.4. Superoxide Radical $\left(\mathrm{O}_{2}^{-}\right)$Scavenging Activity. This test was performed according to Dasgupta and De [38], with modifications. Superoxide radicals were generated using the system nitrotetrazolium blue chloride/nicotinamide adenine dinucleotide (NBT/NADH). All experiments were performed in triplicate. The inhibition capacity (\%) of the photochemical reduction of NBT was calculated using Equation (4), where $A_{\mathrm{c}}$ is the absorbance of the control and $A_{\mathrm{s}}$ is the absorbance of the sample. The concentration required to eliminate $50 \%$ of radical superoxide $\left(\mathrm{IC}_{50}\right)$ was calculated.

$$
\% I=\left[\frac{A_{c}-A_{s}}{A_{c}}\right] \times 100 .
$$

2.5. Animals. Three-month Wistar rats (Rattus norvegicus var. albinus), with body weight between 200 and $330 \mathrm{~g}$, of both sexes were used in the study. The rats were provided by the Department of Physiology and Pharmacology of the Federal University of Pernambuco, Brazil. The animals were housed in cages with open-mesh floors to avoid coprophagy and maintained under controlled lighting ( $12 \mathrm{~h}$ light/dark cycle), temperature $\left(22 \pm 2^{\circ} \mathrm{C}\right)$, and humidity (55-65\%) conditions, receiving diet (Presence, Purina, São Paulo, Brazil) and water ad libitum. In all protocols, the animals underwent gavage and were euthanized in a $\mathrm{CO}_{2}$ chamber (by inhalation). The number of animals was distributed inhomogeneously to form the different groups considering that during the experimental procedures, intercurrences can occur that result in the death of the animal or its exclusion from the group. The experimental protocols were submitted to and approved by the Ethics Committee on Animal Experimentation of the Federal University of Pernambuco (registration number 0016/2016) according to the Guide for the Care and Use of Laboratory Animals of the National Institute of Health (Washington, DC, 2011). 
2.6. Acute Toxicity Study in Rats. The acute toxicity study was performed in female Wistar rats, as described by the Organization for Economic Co-operation and Development (OECD 425) [39], with minor modifications. The animals were randomly divided into two groups ( $n=3$ /group) and deprived of feed for $12 \mathrm{~h}$ with free access to water. Then, the control group received the vehicle $(0.9 \% \mathrm{NaCl}$ solution, $10 \mathrm{~mL} / \mathrm{kg})$, and the treated group received a single oral dose of DELfp $(2000 \mathrm{mg} / \mathrm{kg})$. After administration, the animals were observed individually at intervals of $30,60,120,180,240$, 300 , and $360 \mathrm{~min}$ every day for 14 days. The following parameters were evaluated: behavioral changes, clinical signs of toxicity, water and feed intake, and body weight variation.

\subsection{Gastroprotective Activity}

2.7.1. Ethanol-Induced Ulcer. After $16 \mathrm{~h}$ of fasting, the animals received, orally, $0.9 \% \mathrm{NaCl}$ solution $(10 \mathrm{~mL} / \mathrm{kg}$, negative control, $n=6$ ), pantoprazole ( $40 \mathrm{mg} / \mathrm{kg}, n=7$ ), or DELfp (50, 100,200 , and $400 \mathrm{mg} / \mathrm{kg}, n=6$ ). After $1 \mathrm{~h}$, all groups received the ulcerogenic agent Merck absolute ethanol $(\geq 99.9 \%, 1 \mathrm{~mL}$, orally), according to the method described by Robert et al. [40], with slight modifications. The animals were euthanized in a $\mathrm{CO}_{2}$ chamber $1 \mathrm{~h}$ after induction of the lesions. The stomachs were removed and photographed, and the gastric lesion area was determined using the ImageJ software version 1.4 (Bethesda, MD, USA). The results were expressed as the area of ulcerative lesion $\left(\mathrm{mm}^{2}\right)$. The effective dose $\left(\mathrm{ED}_{50}\right)$ that inhibited $50 \%$ of the ulcerative lesion area was calculated. The glandular portion of the stomachs was used for the determination of lipid peroxidation and nonprotein sulfhydryl compounds and histological analysis.

\subsubsection{Determination of Lipid Peroxidation and Levels of} Nonprotein Sulfhydryl Compounds. The lipid peroxidation index was determined by measuring the levels of thiobarbituric acid reactive substances (TBARS) using the method described by Ohkawa et al. [41], with modifications. The tissues were homogenized in a solution of potassium chloride $(1.15 \% \mathrm{KCl})$ and $3 \mathrm{mM}$ EDTA ( $5 \mathrm{~mL}$ of solution/gram of tissue) and kept in an ice bath. Then, $10 \mathrm{mg}$ of the tissues was added to the reaction medium containing sodium dodecyl sulfate (0.4\% SDS), 7.5\% acetic acid, and thiobarbituric acid $(0.3 \% \mathrm{TBA})(\mathrm{pH} 3.5)$. The reaction tubes were sealed and incubated at $95^{\circ} \mathrm{C}$ for 60 minutes. After cooling under running water, 1 volume of butanol was added for each volume of the reaction solution, and the tubes were centrifuged at $4000 \mathrm{rpm}$ for 10 minutes. The absorbance of the organic phase was measured at $535 \mathrm{~nm}$. The results were corrected for the protein concentration of the homogenate and expressed in nmol of malondialdehyde (MDA)/mg protein.

The levels of nonprotein sulfhydryl (-SH) compounds in the gastric mucosal homogenate were determined using the methodology of Sedlak and Lindsay [42]. The tissue sample from the homogenate obtained for the evaluation of lipid peroxidation (final concentration $50 \mathrm{mg} / \mathrm{mL}$ ) was precipitated in trichloroacetic acid solution (5\% TCA). The supernatant (final concentration $5 \mathrm{mg} / \mathrm{mL}$ ) was then added to the reaction medium containing $400 \mathrm{mM}$ TRIS, $4 \mathrm{mM}$ EDTA,

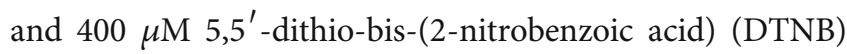
$(\mathrm{pH}$ 8.9). The reaction was incubated at room temperature for 5 minutes, and the absorbance was measured at $412 \mathrm{~nm}$. The result was corrected for the protein concentration of the homogenate, and the concentration of - $\mathrm{SH}$ compounds was expressed in nmol of $\mathrm{GSH} / \mathrm{mg}$ protein.

2.7.3. Histological Analysis. For this analysis, the stomachs were sectioned and fixed in $10 \%$ buffered formalin. Once fixed, the samples were washed with water, immersed in $70 \%$ ethyl alcohol for 3-4 days, and embedded in paraffin. $5 \mu \mathrm{m}$ thick paraffin sections were stained and fixed with hematoxylin/eosin (H\&E). Histological analysis of the gastric sections was performed using a MICRO DIP automated microscopy system.

2.7.4. Acidified Ethanol- (Ethanol/HCl) Induced Ulcer. After 16 hours of fasting, the animals received, orally, $0.9 \% \mathrm{NaCl}$ solution $(10 \mathrm{~mL} / \mathrm{kg}$, negative control, $n=6)$, pantoprazole (40 mg/kg, $n=7)$, or DELfp (100, 200, and $400 \mathrm{mg} / \mathrm{kg}, n=6$ ). After $1 \mathrm{~h}$, all groups received the ulcerogenic agent, $1 \mathrm{~mL}$ of $0.3 \mathrm{M} \mathrm{HCl}$ solution $/ 60 \%$ ethanol, orally, according to the method described by Mizui and Douteuchi [43]. The animals were euthanized $1 \mathrm{~h}$ after the induction of the lesions. The stomachs were removed and photographed, and the gastric lesion area was determined using the ImageJ software version 1.4 (Bethesda, MD, USA). The results were expressed as the area of ulcerative lesion $\left(\mathrm{mm}^{2}\right)$. The effective dose $\left(\mathrm{ED}_{50}\right)$ that inhibited $50 \%$ of the ulcerative lesion area was calculated.

2.7.5. Indomethacin-Induced Gastric Ulcer. After 16 hours of fasting, the animals were given, orally, $0.9 \% \mathrm{NaCl}$ solution $(10 \mathrm{~mL} / \mathrm{kg}$, negative control, $n=6)$, pantoprazole $(40 \mathrm{mg} / \mathrm{kg}$, $n=6)$, or DELfp $(100,200$, and $400 \mathrm{mg} / \mathrm{kg}, n=7)$. After 30 minutes of pretreatment, gastric lesions were induced with indomethacin $(30 \mathrm{mg} / \mathrm{kg}$ subcutaneously) according to the method described by Djahanguiri [44], with modifications. After $6 \mathrm{~h}$ of induction, the stomachs were removed and photographed for the determination of gastric lesions, as previously described.

2.8. Evaluation of Protective Factors of the Gastric Mucosa. Unlike previous gastroprotective protocols, in which three doses were used to show a dose-effect relation of DELfp, in the experiments below, it was aimed at determining the possible mechanism of action. In this sense, the influence of the indicators on the effect of the extract was evaluated: mucus concentration, gastric content, $\mathrm{pH}$, total acidity, and $\mathrm{NO}$ and -SH compounds. Only one dose of DELfp $(200 \mathrm{mg} / \mathrm{kg})$ representing the intermediate dose used in the study was selected, since we suppose that to investigate the mode of action of the extract, it is not necessary to use different doses as the pharmacological mechanism of action tends to be similar to that of different doses of the extract.

2.8.1. Determination of Mucus Concentration in the Gastric Mucosa. Soluble glycosaminoglycan content in the gastric mucosa was investigated using Alcian blue, specific for acid mucins [45]. This experiment was performed according to Raffatullah et al. [46] with slight modifications. After 16 
hours of fasting, the animals received, orally, $0.9 \% \mathrm{NaCl}$ solution $(10 \mathrm{~mL} / \mathrm{kg}$, negative control, $n=7)$, carbenoxolone $(200 \mathrm{mg} / \mathrm{kg}, n=6)$, or DELfp $(200 \mathrm{mg} / \mathrm{kg}, n=8)$. A noninjured control group $(n=6)$ was used in this experiment; animals of this group did not receive treatment but underwent surgical stress. After 1 hour, under anesthesia (xylazine, $6 \mathrm{mg} / \mathrm{kg}$ associated with ketamine, $60 \mathrm{mg} / \mathrm{kg}$, i.p.), the animals were subjected to longitudinal incision for pyloric ligation. After 4 hours, the animals were euthanized, and the esophagus was pinched off so that stomach contents were not lost. The stomachs were removed, washed with distilled water, dried, and opened along the greater curvature, and the gastric contents were collected and weighed. The glandular portion of the stomach was then weighed and stored in a single vessel immersed in $10 \mathrm{~mL}$ of $0.1 \%$ Alcian blue solution. After 2 hours of soaking, the excess dye was removed from the glandular portion of the stomach in two successive washes with $7 \mathrm{~mL}$ of $0.25 \mathrm{~mol} / \mathrm{L}$ sucrose for 15 and 45 minutes. After that, the dye complexed with the gastric wall mucus was removed by sequentially transferring each stomach to $10 \mathrm{~mL} \mathrm{MgCl}_{2}(0.5 \mathrm{~mol} / \mathrm{L})$ and vortexing them for 1 minute at 30-minute intervals, for 2 hours. The stomachs were removed, and the Falcon tubes with the solution were stored in the refrigerator for approximately $8 \mathrm{~h}$. After this interval, the tubes were shaken for 1 minute, then collected and added to $4 \mathrm{~mL}$ of ethyl ether, and vigorously vortexed for 2 minutes. The emulsion obtained was centrifuged at $3600 \mathrm{rpm}$ for $10 \mathrm{~min}$. The tubes were placed in an ice bath, and the absorbance of the aqueous layer was obtained by spectrophotometric reading at $595 \mathrm{~nm}$. The amount of blue dye extracted per gram of glandular tissue was then calculated. The result was expressed as $\mathrm{mg}$ Alcian/g tissue.

2.8.2. Determination of Gastric Acid Secretion. This assay was performed according to the protocol described by Shay et al. [47], with slight modifications. The animals were divided into 4 groups and fasted for 16 hours with free access to $5 \%$ glycoside water solution. For pyloric ligation, the animals were anesthetized (xylazine $6 \mathrm{mg} / \mathrm{kg}$ associated with ketamine, $60 \mathrm{mg} / \mathrm{kg}$, i.p.), the abdomen was opened for exposure of the stomach, and the pylorus was tied with a suture. Immediately after ligation, the animals received an intraduodenal solution of $0.9 \% \mathrm{NaCl}(0.1 \mathrm{~mL} / 100 \mathrm{~g}$, negative control, $n=6)$, ranitidine $(60 \mathrm{mg} / \mathrm{kg}, n=7)$, or DELfp $(200 \mathrm{mg} / \mathrm{kg}, n=6)$. The abdominal wall was sutured, and four hours after pylorus ligation, the animals were euthanized. The noninjured control group $(n=5)$ was used in this experiment; animals of this group did not receive intraduodenal treatment but underwent surgical stress. One animal in this group died of anesthetic complications. Gastric secretion was collected and centrifuged at $1500 \mathrm{rpm}$ for $30 \mathrm{~min}$. Gastric content (g), pH, and total acidity (mEquiv. $\left.\left[\mathrm{H}^{+}\right] / \mathrm{mL} / 4 \mathrm{~h}\right)$ values were estimated.

2.8.3. Involvement of Nitric Oxide (NO) and Sulfhydryl (-SH) Compounds in Gastroprotection. To investigate the influence of nitric oxide and endogenous sulfhydryl compounds on gastroprotection, male rats were distributed in 12 groups and remained in the fasted state for 16 hours. All groups were pretreated intraperitoneally, six groups received $0.9 \% \mathrm{NaCl}$ solution $(n=6)$, three groups received N-nitro-L-arginine methyl ester (L-NAME, $70 \mathrm{mg} / \mathrm{kg}$, i.p., $n=8$ ), an inhibitor of the NO-synthase enzyme, and three groups received $\mathrm{N}$ ethylmaleimide (NEM, $10 \mathrm{mg} / \mathrm{kg}$, i.p., $n=6$ ), a blocker of $\mathrm{SH}$ compounds responsible for the maintenance of the mucosal barrier integrity $[48,49]$. After $30 \mathrm{~min}$ of pretreatment, $\quad 0.9 \% \mathrm{NaCl}$ solution (control), carbenoxolone $(100 \mathrm{mg} / \mathrm{kg})$, or DELfp $(200 \mathrm{mg} / \mathrm{kg})$ was given orally. After $1 \mathrm{~h}$, all animals received Merck absolute ethanol $(\geq 99.9 \%$, $1 \mathrm{~mL}$, orally) for the induction of gastric ulcers. After $1 \mathrm{~h}$ of administration of the ulcerogenic agent, the animals were euthanized in a $\mathrm{CO}_{2}$ chamber. The stomachs were removed for the determination of the superficial area of the gastric lesion in the ImageJ software (Bethesda, MD, USA). The results were expressed in $\mathrm{mm}^{2}$.

\subsection{Evaluation of the Healing Properties of DELfp}

2.9.1. Acetic Acid-Induced Gastric Ulcer. The induction of chronic ulcer was based on the study of Takagi et al. [50], with some modifications. The animals were divided into four groups and fasted for 16 hours. After fasting, the animals were anesthetized (xylazine, $6 \mathrm{mg} / \mathrm{kg}$ associated with ketamine, $60 \mathrm{mg} / \mathrm{kg}$, i.p.) for surgical exposure of the stomach, and then, $0.05 \mathrm{~mL}$ of $30 \%$ acetic acid was injected in the subserous layer of the external wall of the stomach. One day after surgery, daily treatment was started and the animals were treated orally once a day for 14 consecutive days with $0.9 \% \mathrm{NaCl}$ solution (negative control, $n=6$ ), ranitidine $(60 \mathrm{mg} / \mathrm{kg}, n=6)$, or DELfp $(200 \mathrm{mg} / \mathrm{kg}, n=8)$. The noninjured control group $(n=6)$, in which the animals received no treatment but underwent surgical stress, with incision and suture of the abdominal wall, was used in this experiment. During treatment, the animals were observed for signs of toxicity such as piloerection, diarrhea, changes in locomotor activity, or mortality, and body weight was recorded. On day 15 , the rats were euthanized, the stomachs were removed and photographed, and the lesions were measured in the ImageJ software (Bethesda, MD, USA). The results were expressed as the total area of ulcerative lesions $\left(\mathrm{mm}^{2}\right)$.

2.9.2. Histological Analysis. The stomachs with ulcers were sectioned and fixed in $10 \%$ buffered formalin. Once fixed, the samples were washed with water, immersed in $70 \%$ ethyl alcohol for 3-4 days, and embedded in paraffin. $5 \mu \mathrm{m}$ thick paraffin sections were fixed and stained with hematoxyli$\mathrm{n}$ /eosin (H\&E) and Masson's trichrome (TM) staining. The histological analysis of the gastric sections was made using a MICRO DIP automated microscopy system.

2.10. Evaluation of Anti-Helicobacter pylori Activity. The activity on bacterial growth was evaluated through minimum inhibitory concentration (MIC) by the broth microdilution technique and minimum bactericidal concentration (MBC) according to the standard established by the Clinical and Laboratory Standards Institute (CLSI) [51] with modifications [52]. The assays were performed with the Helicobacter pylori ATCC 43504 strain (sensitive to amoxicillin and resistant to metronidazole), grown initially on plates containing Columbia agar supplemented with $5 \%$ ram blood incubated 


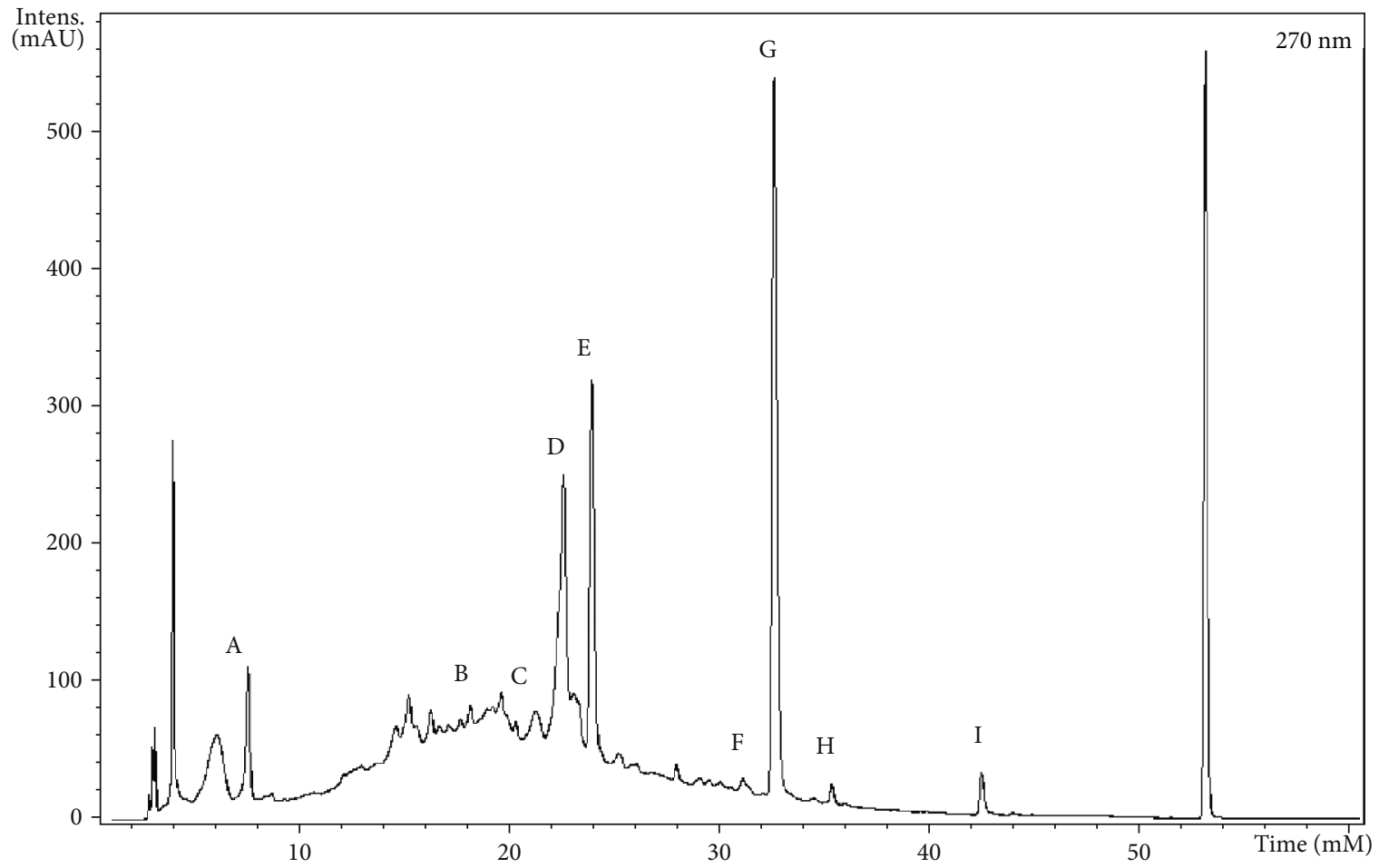

Figure 1: Chromatogram of the L. ferrea extract at $270 \mathrm{~nm}$ : (A) galloylquinic acid, (B) galloyl-HHDP-hex, (C) brevifolin carboxylic acid, (D) valoneic acid dilactone, (E) gallic acid derivative, (F) ellagic acid derivative (ellagic acid hex-), (G) ellagic acid, (H) ellagic acid derivative, and (I) dihydroisovaltrate.

for 72 hours at $37^{\circ} \mathrm{C}$ in an atmosphere containing $10 \% \mathrm{CO}_{2}$. After that, the colonies were transferred to Brain Heart Infusion (BHI) broth (Merck Millipore cod. 110493, Darmstadt, Germany) supplemented with $10 \%(v / v)$ fetal bovine serum (Sigma-Aldrich cod. F2561; St. Louis, MO, USA) and incubated under the same conditions.

For the MIC assay, $100 \mu \mathrm{L}$ of different concentrations of the samples ( 32 to $1024 \mu \mathrm{g} / \mathrm{mL}$ ) was added to each well of a 96-well microplate and the same volume of bacterial suspension (dilution $1: 20$ of the $0.5 \mathrm{McF}$ arland scale) in supplemented BHI. For bacterial growth control, the bacterial suspension and BHI medium were added; for the negative control, only samples and supplemented BHI medium were added. Growth inhibition was determined by the absorbance difference at $620 \mathrm{~nm}$ obtained before and after incubation for 72 hours at $37^{\circ} \mathrm{C} / 10 \% \mathrm{CO}_{2}$. CIM was graphically defined as the lowest concentration of samples that induced a sharp decline in absorbance (90\% inhibition).

MBC was determined by the lower concentration of samples capable of inhibiting colony formation in Columbia Agar plates containing 5\% sheep blood (incubated at $37^{\circ} \mathrm{C} / 10 \% \mathrm{CO}_{2}$ for $72 \mathrm{~h}$ ) corresponding to the microplate wells of the MIC assay without apparent growth. Amoxicillin (Sigma-Aldrich cod. A8523; St. Louis, MO, USA) was used as the standard for anti-H. pylori control.

2.11. Statistical Analysis. Results were expressed as mean \pm standard error of the mean (SEM). Differences between means were determined by analysis of variance (ANOVA) followed by Dunnett's multiple comparison test.
The level of significance for rejection of the null hypothesis was $5 \%(p<0.05)$. In the acute toxicity protocols and the influence of nitric oxide and sulfhydryl compounds on gastroprotection, the unpaired Student $t$-test was used to test for statistical differences between the two groups. Statistical analyses were performed in the GraphPad Prism version 7.0 (GraphPad Software, Inc., La Jolla, CA, USA).

\section{Results and Discussion}

\subsection{Phytochemical Profile}

3.1.1. High-Performance Liquid Chromatography (HPLC$M S)$. Chromatographic analysis of the dry extract of $L$. ferrea pods suggested the presence of nine compounds: (A) galloylquinic acid (7.4 min), (B) galloyl-HHDP-hex (19.8 min), (C) brevifolin carboxylic acid (20.2 min), (D) valoneic acid dilactone (22.0 $\mathrm{min})$, (E) gallic acid derivative (23.9 min), (F) ellagic acid derivative (ellagic acid hex-) (32.6 min), (G) ellagic acid (32.5 min), (H) ellagic acid derivative (35.3 $\mathrm{min})$, and dihydroisovaltrate $(42.3 \mathrm{~min}$ ) (see Figure 1).

The compounds were identified by similarity between ultraviolet (UV) absorption spectra, mass/charge ratio, and fragmentation profile $\left(\mathrm{MS}^{2}\right)$ with corresponding values in the literature (see Table 1).

According to the UV chromatogram at $270 \mathrm{~nm}$, the main constituents of the DELfp are hydrolyzable tannins and phenolic compounds, since they have the same fragmentation 


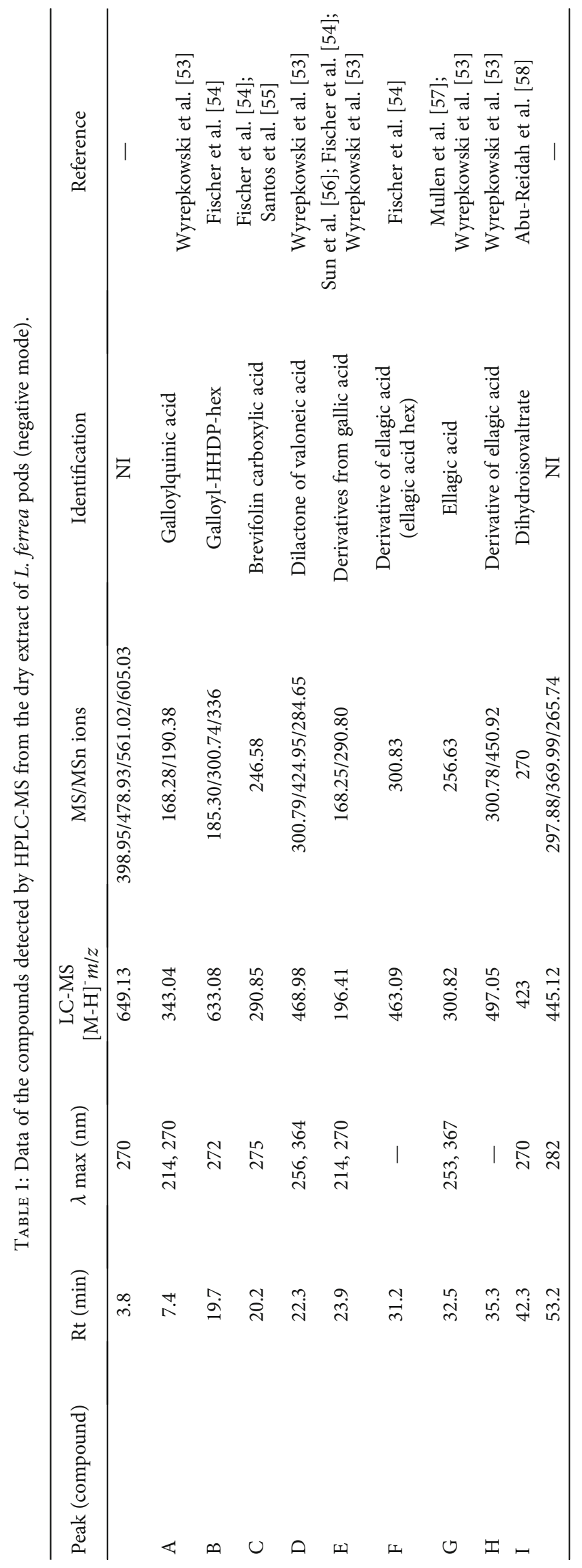




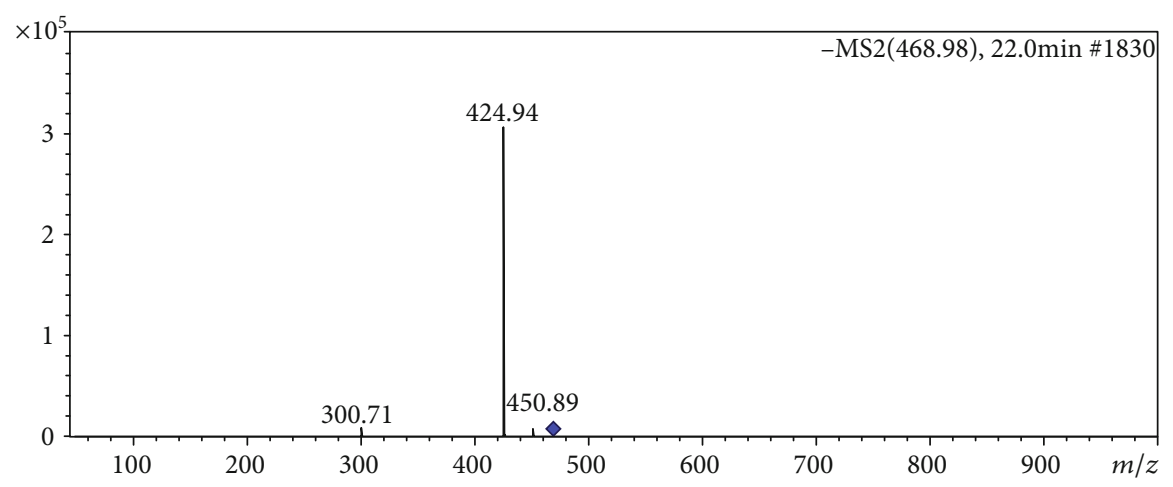

(a)

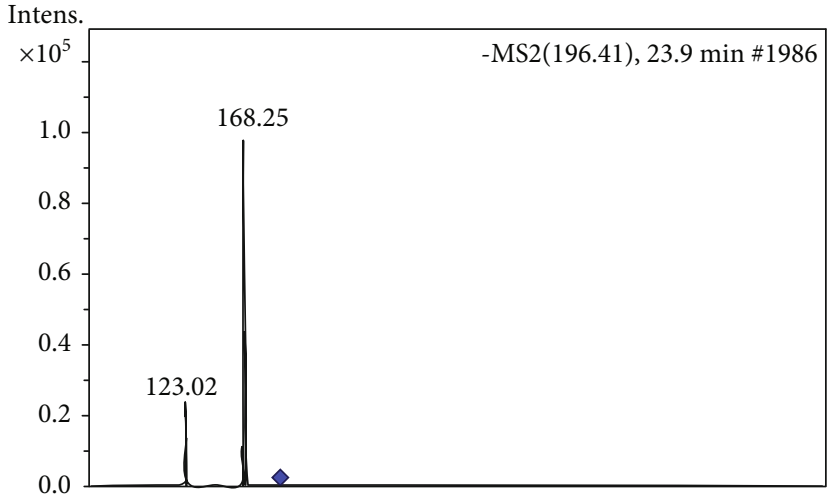

(b)

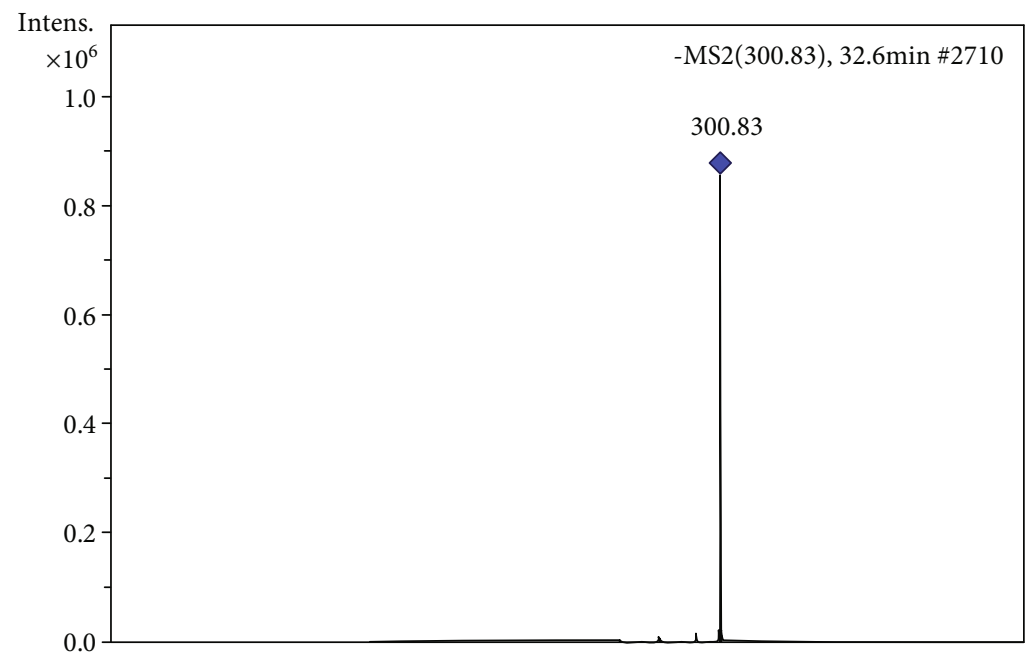

(c)

FIGURE 2: MS/MS spectra obtained from the chromatograms and the proposed identified compounds: (a) valoneic acid dilactone; (b) gallic acid derivative; (c) ellagic acid.

profile described by Wyrepkowski et al. [53], Fischer et al. [54], Santos et al. [55], Sun et al. [56], Mullen et al. [57], and Abu-Reidah et al. [58].

Hydrolyzable tannins are readily hydrolyzed in vivo by the action of acids and/or enzymes releasing gallic acid and ellagic acid units $[59,60]$. Gallic acid has anti-inflammatory and antioxidant activity, and ellagic acid has demonstrated antimutagenic and antioxidant activity [60].
Vasconcelos et al. [26] identified hydrolyzable tannins (gallic acid and ellagic acid) as the major compounds in the aqueous extract of the $C$. ferrea stem bark and related them to the reduction of oxidative stress in the hepatic tissue of diabetic rats.

The presence of the valoneic acid dilactone (VAD) (D) was suggested in DELfp, with $\mathrm{m} / z 468.98$ and fragmentation profile $m / z$ 300.71, 424.94, and 450.89 (e.g., in Figure 2(a)). 
TABLE 2: In vitro antioxidant activity $\mathrm{IC}_{50}(\mu \mathrm{g} / \mathrm{mL})$ of the dry extract of $L$. ferrea pods (DELfp) and antioxidant standards.

\begin{tabular}{lcccc}
\hline Sample & $\mathrm{DPPH}^{+}$ & $\mathrm{ABTS}^{+}$ & TAA & SRSA \\
& $\mathrm{IC}_{50}(\mu \mathrm{g} / \mathrm{mL})$ & $\mathrm{IC}_{50}(\mu \mathrm{g} / \mathrm{mL})$ & $\mathrm{IC}_{50}(\mu \mathrm{g} / \mathrm{mL})$ & 63.60 \\
$\mathrm{IELfp}$ & 28.96 & 145.10 & $\mathrm{NT}$ & 119.64 \\
Trolox & 53.20 & 199.27 & $\mathrm{NT}$ & $\mathrm{NT}$ \\
Ascorbic acid & $\mathrm{NT}$ & $\mathrm{NT}$ & 500.00 & $\mathrm{NT}$ \\
\hline
\end{tabular}

DPPH: 2,2-diphenyl-1-picrylhydrazyl radical; ABTS: 2',2-azino-bis(3-ethylbenzthiazoline-6-sulfonate) radical; TAA: total antioxidant activity; SRSA: superoxide radical scavenging assay; NT: not tested.

VAD presents in its structure etheric ellagic acid, by oxidative coupling with gallic acid [61].

The ion derived from deprotonation of the molecule at $m$ Iz 196.41 (E) was identified in Rt of 23.9 minutes, with fragmentation spectra $\mathrm{m} / \mathrm{z} \quad 168.25$ and 123.02 (e.g., in Figure 2(b)). Wyrepkowski et al. [53] identified this compound as ethyl gallate, derived from gallic acid, in the chromatographic analysis of the $C$. ferrea stem bark.

Ellagic acid (G), observed at $\mathrm{m} / \mathrm{z} 300.82$, produced a $\mathrm{m} / \mathrm{z}$ 256.63 fragment during fragmentation (e.g., in Figure 2(c)), which is in line with the results found by Wyrepkowski et al. [53] who also detected the $m / z 301$ ion as ellagic acid, with the fragmentation profile $\mathrm{m} / z 257\left[\mathrm{M}-\mathrm{H}-\mathrm{CO}_{2}\right]^{-}, \mathrm{m} / \mathrm{z}$ $229\left[\mathrm{M}-\mathrm{H}-\mathrm{CO}_{2}-\mathrm{CO}\right]^{-}$, and $\mathrm{m} / z 185\left[\mathrm{M}-\mathrm{H}-2 \mathrm{CO}_{2}-\mathrm{CO}\right]^{-}$.

Brito et al. [62] found that gallic acid and ellagic acid are isolated gastric protectors, but when associated, these compounds act synergistically to protect the mucosa in preclinical models of gastric lesions.

The phytochemical analysis of DELfp allowed the quantification of total phenolic compounds and flavonoids and evaluation of the antioxidant and antiulcerogenic activity of the extract.

\subsection{Quantification of Secondary Metabolite Classes in DELfp.} Phenolic compounds exhibit antioxidant activity due to the ability to donate hydrogen or electrons and formation of stable intermediate radicals that prevent lipid oxidation [36]. The content of phenolic compounds was determined by an assay using the Folin-Ciocalteu reagent, where the intensity of the blue complex formed indicates the total content of phenolic compounds and is related to a greater number of hydrogenation groups present [63].

The quantification of total phenolic compounds in DELfp was $951.39 \pm 0.01 \mathrm{mg}$ EAG/g. Silva et al. [64] analyzed three plant species for antioxidant capacity and DNA protection and observed that $L$. ferrea fruits had the ability to eliminate the damage to DNA produced by hydroxyl radicals, and they associated this antioxidant activity with the high content of phenolic compounds of the species $(460.00 \pm 4.16 \mathrm{mg}$ EAG/g).

Port's et al. [65] evaluated the phenolic compounds of Chrysobalanus icaco (51.30 mg EAG/g), Lagerstroemia speciosa (47.54 mg EAG/g), and L. ferrea (68.13 mg EAG/g) from the Amazon region. L. ferrea presented the highest content of polyphenols and the highest antioxidant capacity among the studied species.

Flavonoids represent a large group of low molecular weight phenolic substances with chemical structures and
TABLE 3: Effect of the dry extract of L. ferrea pods (DELfp) on food consumption, water consumption, and body weight in female rats for 14 days.

\begin{tabular}{lcc}
\hline Parameter & $\begin{array}{c}\text { Control } \\
(0.9 \% \mathrm{NaCl})\end{array}$ & $\begin{array}{c}\text { DELfp } \\
(2000 \mathrm{mg} / \mathrm{kg})\end{array}$ \\
\hline Food consumption $(\mathrm{g})$ & $16.75 \pm 1.86$ & $17.98 \pm 0.71$ \\
Water consumption $(\mathrm{mL})$ & $31.96 \pm 1.05$ & $37.64 \pm 1.19^{*}$ \\
Initial body weight $(\mathrm{g})$ & $216.70 \pm 10.09$ & $212.70 \pm 18.70$ \\
Final body weight $(\mathrm{g})$ & $222.00 \pm 4.61$ & $222.70 \pm 17.24$ \\
\hline
\end{tabular}

Values represent the mean $\pm \operatorname{SEM}(n=3$ /group). Statistically different when compared to the control group, Student's $t$-test for unpaired samples; ${ }^{*} p<0.02$

diverse characteristics [66]. They are responsible for protecting plants from ultraviolet (UV) radiation and phytopathogens [67]. They also present important biological activities, such as antioxidant activity, through elimination of free radicals [67], and gastroprotective activity, with antisecretory and cytoprotective activities [3]. The total flavonoid content in the DELfp was $35.35 \mathrm{mg} \mathrm{EQ/g} \mathrm{extract.}$

Flavonoids are known to inhibit the enzymatic activity of histidine decarboxylase [68] and thus reduce the formation of histamine in the gastric mucosa, a substance that directly stimulates parietal cells and pepsinogen responsible for the secretion of hydrochloric acid and pepsin, respectively [69].

Another substance involved in gastric damage is plateletactivating factor (PAF), an endogenous phospholipid that causes gastrointestinal ulceration [70] and predisposes the stomach to damage caused by ethanol directly applied to the gastric mucosa [71]. Intraperitoneal administration of quercetin, rutin, and kaempferol $(25-100 \mathrm{mg} / \mathrm{kg})$ inhibited the gastric content of PAF [69].

3.3. Antioxidant Activity In Vitro. Antioxidants protect the body against the oxidative damage involved in various diseases, which are believed to be caused or related to excess free radicals in the body, including cancer, hypertension, heart disease, and diabetes $[72,73]$. Oxidative stress has a role in the etiology of gastrointestinal diseases. The increase in oxidizing agents and the overload of endogenous antioxidants favor the process of gastric ulceration [13].

Studies indicate that there is no single method capable of quantitatively and accurately evaluating antioxidant properties. As the various methodologies differ in their mechanisms 


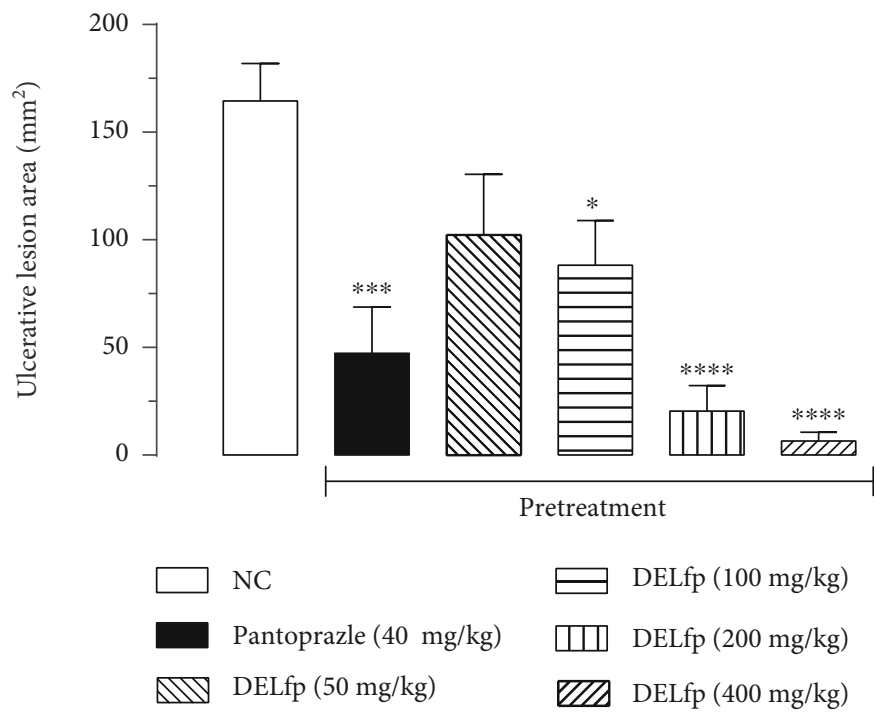

Figure 3: Gastroprotective effect of the dry extract of $L$. ferrea pods (DELfp) on absolute ethanol-induced gastric lesions in Wistar rats. The animals received, orally, $0.9 \% \mathrm{NaCl}$ solution (negative control, NC), pantoprazole (40 mg/kg), or DELfp (50, 100, 200, and 400 mg/kg). Results are expressed as mean \pm SEM (5-7 animals/group). Statistically different when compared to the negative control group, ANOVA followed by Dunnett's multiple comparison test; ${ }^{*} p<0.05,{ }^{* * *} p<0.001$, and ${ }^{* * * *} p<0.0001$.

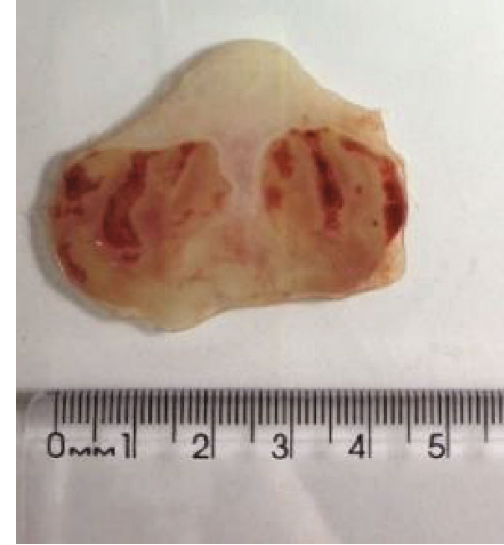

(a)

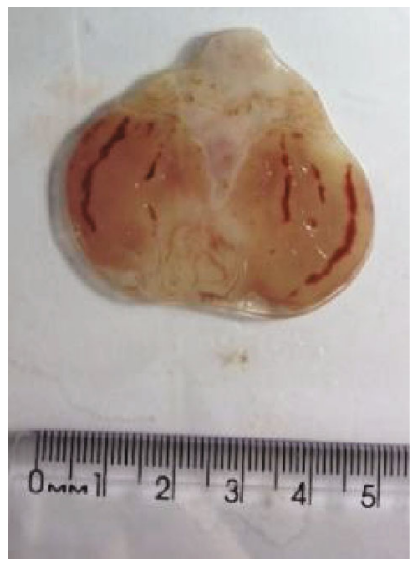

(d)

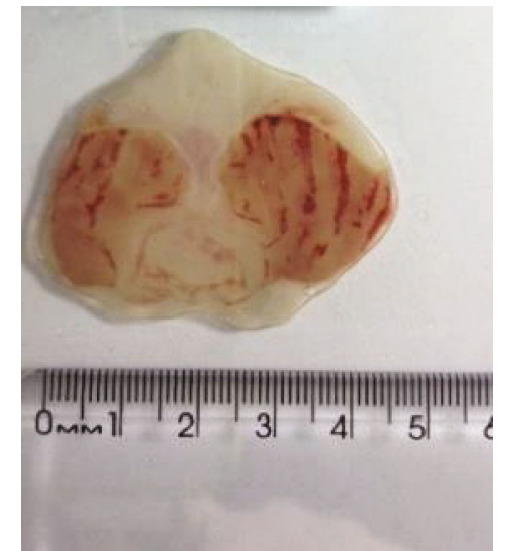

(b)

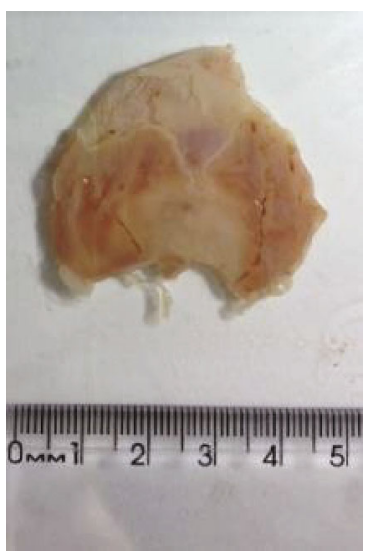

(e)

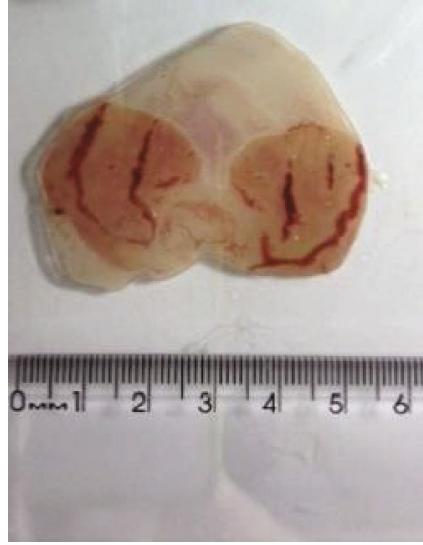

(c)

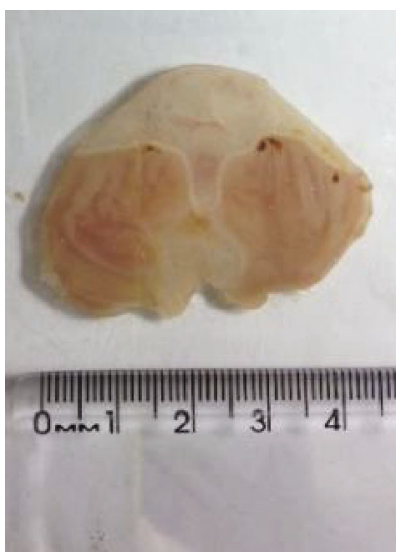

(f)

Figure 4: Typical photographs of the gastroprotective effect of the dry extract of L. ferrea pods (DELfp) on absolute ethanol-induced gastric lesions in Wistar rats. Top panel: (a) negative control, (b) pantoprazole (40 mg/kg), and (c) DELfp (50 mg/kg). Bottom panel: DELfp $(100,200$, and $400 \mathrm{mg} / \mathrm{kg}$, respectively) (d, e, f). 
TABLE 4: Effect of oral pretreatment with the dry extract of $L$. ferrea pods (DELfp) on absolute ethanol-induced gastric lesions in Wistar rats.

\begin{tabular}{lcc}
\hline Pretreatment & $\begin{array}{c}\text { LPO (nmol of } \\
\text { MDA/mg protein) }\end{array}$ & $\begin{array}{c}\text { SH groups } \\
(\mathrm{nmol} / \mathrm{mg} \text { protein })\end{array}$ \\
\hline Negative control (NC) & $0.86 \pm 0.12$ & $470.00 \pm 23.75$ \\
Pantoprazole $(40 \mathrm{mg} / \mathrm{kg})$ & $0.49 \pm 0.06^{*}$ & $861.70 \pm 44.80^{* * * *}$ \\
DELfp $(100 \mathrm{mg} / \mathrm{kg})$ & $0.48 \pm 0.07^{* *}$ & $754.91 \pm 72.48^{* *}$ \\
DELfp $(200 \mathrm{mg} / \mathrm{kg})$ & $0.55 \pm 0.04^{*}$ & $766.60 \pm 69.39^{* *}$ \\
DELfp $(400 \mathrm{mg} / \mathrm{kg})$ & $0.48 \pm 0.08^{*}$ & $409.70 \pm 23.04$ \\
\hline
\end{tabular}

LPO: lipid peroxidation; SH groups: nonprotein sulfhydryl groups. Results are expressed as mean \pm SEM ( $n=6-7$ /group). Statistically different when compared to the negative control group, ANOVA followed by Dunnett's multiple comparison test; ${ }^{*} p<0.05,{ }^{* *} p<0.01$, and ${ }^{* * * *} p<0.0001$.

of action, they are considered complementary in the study of the antioxidant potential of plants $[74,75]$.

In this study, different types of assays were used to evaluate the potential antioxidant of DELfp. The results on the inhibition of free radical at $\mathrm{IC}_{50}$ values are shown in Table 2. From the $\mathrm{IC}_{50}$ values described in the table, it is observed that both in the reduction of the DPPH radical and in the ABTS radical elimination capacity, the DELfp presented higher antioxidant power when compared to the Trolox standard. In addition, it also presented total antioxidant activity (TAA) and antioxidant activity to superoxide radicals (SRSA).

In the study of Port's et al. [65], L. ferrea leaves had a capacity to reduce the DPPH radical, presenting an $\mathrm{IC}_{50}$ value of $46.70 \mu \mathrm{g} / \mathrm{mL}$. Hassan et al. [76] found a remarkable scavenging activity of the DPPH radical by the ethanolic extract of C. ferrea, compared with ascorbic acid. The antioxidant capacity of the extract $\left(\mathrm{IC}_{50}\right)$ was determined $(12.45 \pm 2.86 \mu \mathrm{g} / \mathrm{mL})$.

3.3.1. Total Antioxidant Activity. The total antioxidant activity (\%TAA) of DELfp at different concentrations (31.25$1000 \mu \mathrm{g} / \mathrm{mL}$ ) was $0.18 \pm 0.04-76.10 \pm 1.63 \%$. Similarly, Silva et al. [64] found that the total antioxidant activity (\%TAA) of the hydroalcoholic extract of fruits of $L$. ferrea was $38.06 \pm 2.04 \%$ in relation to the activity of the standard, ascorbic acid.

3.3.2. Superoxide Radical $\left(\mathrm{O}_{2}^{-}\right)$Scavenging Activity. The extract of $L$. ferrea was able to scavenge the superoxide radical formed, presenting $\mathrm{IC}_{50}=119.64 \mu \mathrm{g} / \mathrm{mL}$. This activity is important to prevent the damages generated by oxidative stress. Silva et al. [64] showed a significant and linear correlation between the phenolic content of $L$. ferrea fruits and the assays $\mathrm{P}-\mathrm{Mo}$ and $\mathrm{O}_{2}{ }^{-}$scavenging activity, with $\mathrm{IC}_{50}=$ $16.66 \pm 2.91 \mu \mathrm{g} / \mathrm{mL}$ by the method of Shukla et al. [77], thus indicating that the phenolic compounds are the main contributors to the antioxidant activity of the species.

The data obtained indicate that the DELfp presents medicinal potential and can be used in the prevention of several diseases associated with oxidative stress, through its antioxidant activity.
3.4. Acute Toxicity. Acute toxicity $\left(\mathrm{LD}_{50}\right)$ is a test that assesses the toxic potential of a substance. Although this test can be used for plant extracts, there are peculiarities (e.g., place of collection of plant material, temperature, altitude, and soil) that should be taken into consideration, as they may influence the result. Therefore, we repeat the test, even knowing previous studies.

Administration of DELfp $(2000 \mathrm{mg} / \mathrm{kg}$, orally) did not cause death and behavioral changes during the 14 days of observation in female Wistar rats. Thus, $\mathrm{LD}_{50}$ was greater than $2000 \mathrm{mg} / \mathrm{kg}$. The extract did not cause changes in the food consumption and body weight gain of the animals but led to higher water consumption (17.8\%) compared to the control group (see Table 3).

Freitas et al. [78] evaluated in mice the acute toxicity of the crude extract and purified fraction of $L$. ferrea pods at doses of 300 and $2000 \mathrm{mg} / \mathrm{kg}$ and found no deaths or alterations in the evaluated parameters.

In our study, we observed increased water consumption in the DELfp group $(2000 \mathrm{mg} / \mathrm{kg})$. However, toxicological studies conducted in our laboratory (not yet published) showed that oral treatment for 30 days with DELfp $(1000 \mathrm{mg} / \mathrm{kg})$ in female rats did not change water consumption. In addition, it did not alter renal function indicators such as blood urea nitrogen, albumin, creatinine, and uric acid. Despite this information, it cannot be discarded that the presence of many secondary metabolites present in the extract $(2000 \mathrm{mg} / \mathrm{kg})$ can interfere with physiological mechanisms at a metabolic level or in the central nervous system inducing polydipsia. In this sense, further studies are needed to clarify the mechanism involved in increased water consumption.

Kobayashi et al. [79] evaluated in rats the acute toxicity of the ethanolic extract of $L$. ferrea pods $(5000 \mathrm{mg} / \mathrm{kg}$ ), and the results showed no death or signs of toxicity in the animals.

The gastroprotective activity of DELfp was evaluated by means of experimental models of absolute ethanol-, acidified ethanol-, and indomethacin- (NSAID) induced ulcers. These models are well described in the literature [15], and the lesions occur predominantly in the glandular portion of the stomach [80]. Reactive oxygen species contribute to the pathogenesis of these lesions, especially when they are caused by ethanol $[81,82]$.

3.5. Ethanol-Induced Ulcer. Administration of DELfp inhibited significantly the formation of absolute ethanol-induced lesions (see Figures 3 and 4 ) at $46.36,87.56$, and $95.99 \%$ in animals pretreated with the extract at the doses of 100, 200, and $400 \mathrm{mg} / \mathrm{kg}$, respectively, when compared to the negative control group (NC, $164.50 \pm 17.38 \mathrm{~mm}^{2}$ ). The $\mathrm{ED}_{50}$ value was $113.7 \mathrm{mg} / \mathrm{kg}$. Rats treated with pantoprazole presented a gastroprotection of $71.20 \%$ of the injured area.

Oral administration of ethanol causes hemorrhagic lesions in the gastric mucosa, extensive submucosal edema, infiltration of inflammatory cells, and loss of epithelial cells [83]. The damage to the gastric mucosa caused by ethanol impairs microcirculation, damaging the endothelium of the capillary vessels and causing microvascular stasis with reduction of tissue oxygen [84, 85]. This 


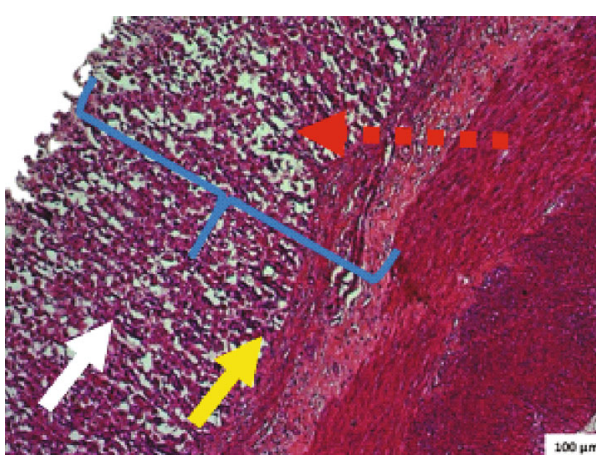

(a)

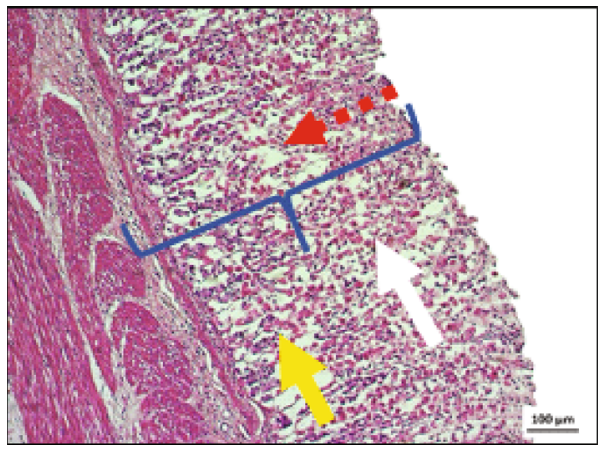

(c)

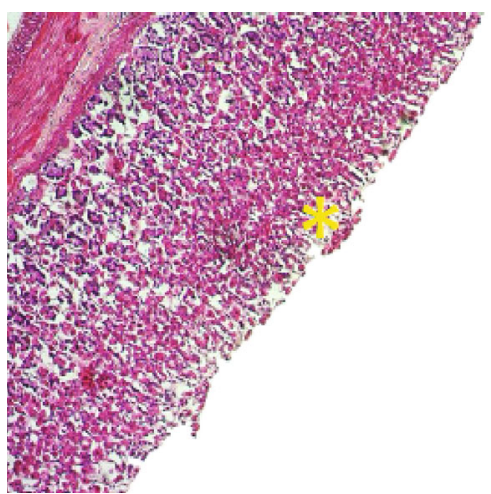

(e)

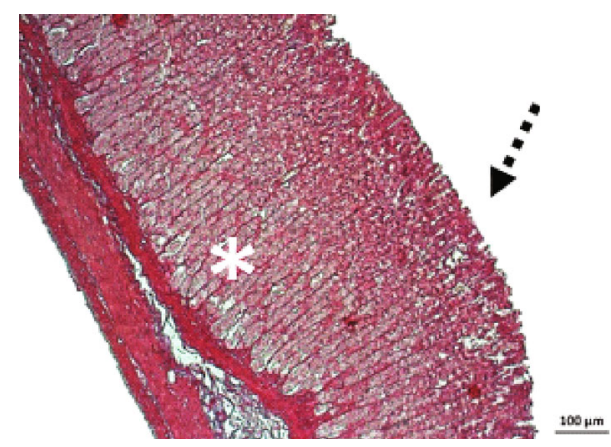

(b)

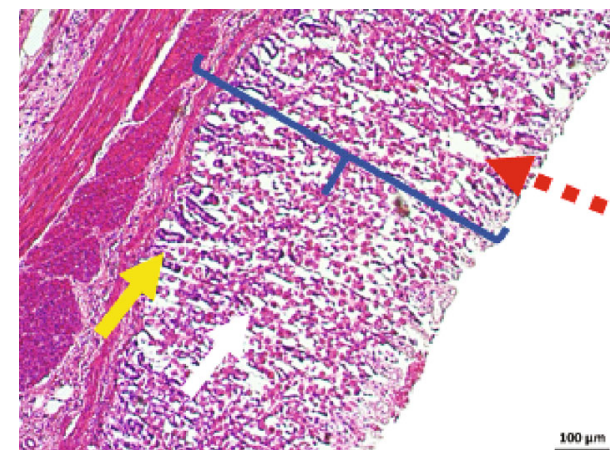

(d)

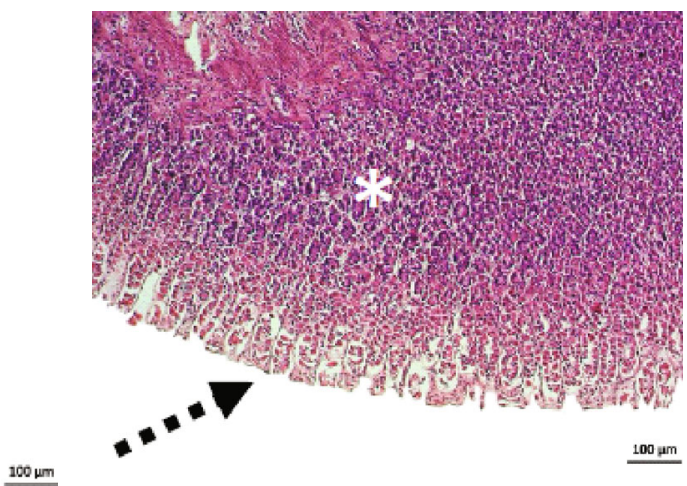

(f)

Figure 5: Histopathology of the gastric mucosa of rats from the experimental groups pretreated with $0.9 \% \mathrm{NaCl}$ (negative control, a), pantoprazole (40 mg/kg, b), and dry extract of L. ferrea pods (DELfp 50, 100, 200, and $400 \mathrm{mg} / \mathrm{kg}$; c, d, e, and f, respectively) in ethanolinduced ulcer. White arrows indicate disorganization of the simple columnar epithelium in the gastric cavities. Yellow arrows indicate congestion of blood capillaries. " $\{$ " indicates necrosis of the gastric mucosa. White asterisks $(*)$ indicate well-preserved gastric glands. The yellow asterisk $(*)$ indicates the unpreserved gastric mucosa with exfoliation of the simple columnar epithelium. Dotted black arrows indicate the preserved gastric mucosa, and dotted red arrows indicate edema.

ulcerogenic agent still inhibits the production of prostaglandins, decreases mucus production [8], and induces free radical formation, increasing lipid peroxidation in the mucosa [86].

Reactive oxygen species have a role in the pathogenesis of gastric ulcer, also when these lesions are caused by ethanol. Ethanol leads to increased superoxide anions, hydroxyl radicals, and lipid peroxidation in the gastric mucosa, inducing intracellular oxidative stress [81, 82, 87].

Pretreatment with DELfp $(100,200$, and $400 \mathrm{mg} / \mathrm{kg}$, orally) and pantoprazole $(40 \mathrm{mg} / \mathrm{kg})$ decreased lipid peroxidation levels by $44.19,36.05,44.19$, and $43.03 \%$, respectively, when compared to the negative control group
(NC, $0.86 \pm 0.12$ ) (see Table 4). The chromatographic analysis of DELfp suggests the presence of compounds with antioxidant activity, which is promising in the treatment of gastric ulcers.

Malondialdehyde (MDA) is a marker of oxidative damage in physiological systems [88], resulting from lipid oxidation that occurs through a free-radical chain mechanism [89]. Caldas et al. [90] and Brito et al. [62] showed that compared to the levels observed in noninjured animals, animals subjected to ethanol-induced damage exhibited an increase in malondialdehyde (MDA) levels, as well as a reduction in the levels of nonprotein sulfhydryl $(-\mathrm{SH})$ compounds. 


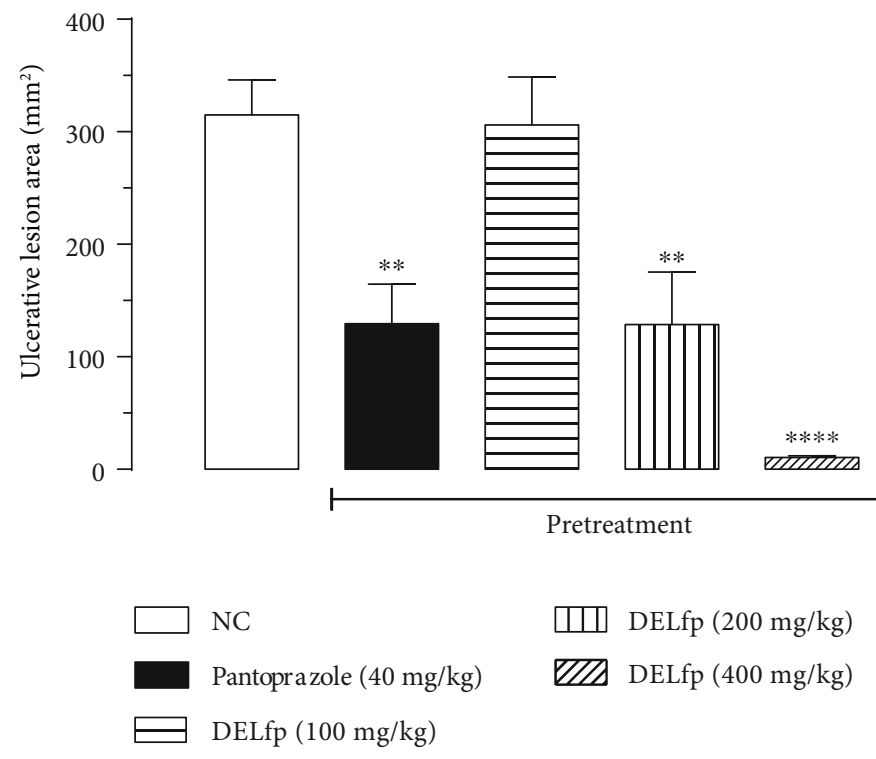

FIGURE 6: Gastroprotective effect of the dry extract of $L$. ferrea pods (DELfp) on ethanol/HCl-induced gastric lesions in Wistar rats. Animals received, orally, $0.9 \% \mathrm{NaCl}$ (negative control, NC), pantoprazole $(40 \mathrm{mg} / \mathrm{kg}$ ), or DELfp (100, 200, and $400 \mathrm{mg} / \mathrm{kg})$. Results are expressed as mean \pm SEM (6-7 animals/group). Statistically different when compared to the negative control group, ANOVA followed by Dunnett's multiple comparison test; ${ }^{* *} p<0.01$ and ${ }^{* * *} p<0.0001$.

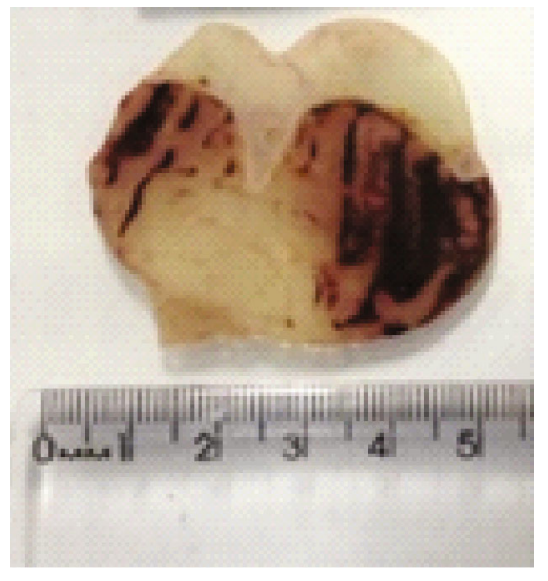

(a)

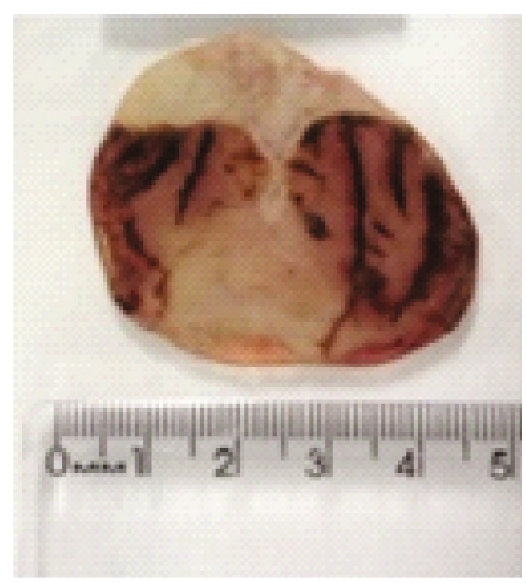

(c)

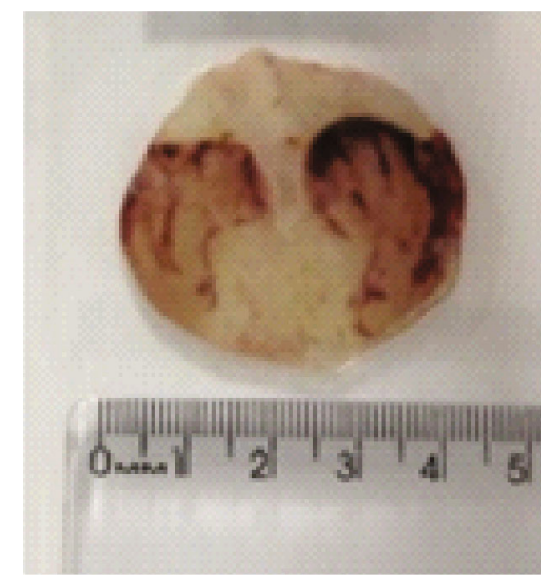

(b)

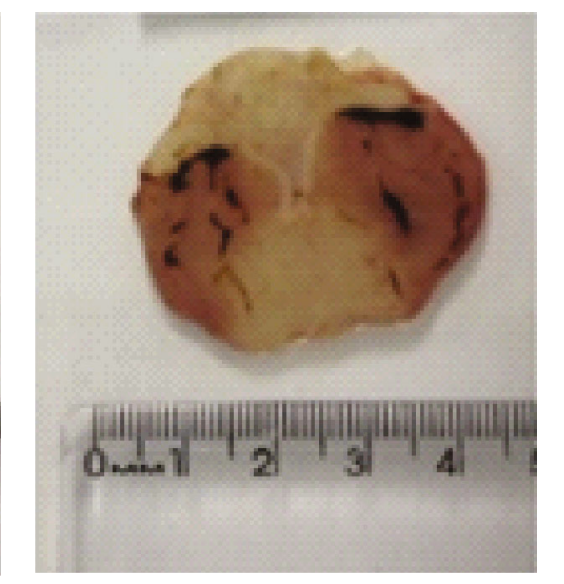

(d)

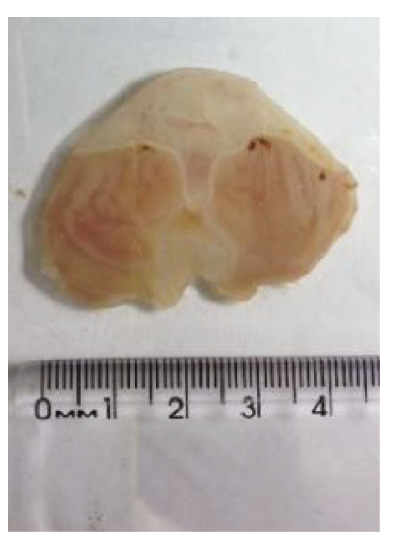

(e)

Figure 7: Typical photographs of the gastroprotective effect of the dry extract of $L$. ferrea pods (DELfp) on ethanol/HCl-induced gastric lesions in Wistar rats: (a) negative control, (b) pantoprazole (40 mg/kg), and (c, d, e) DELfp (100, 200, and $400 \mathrm{mg} / \mathrm{kg}$, respectively). 


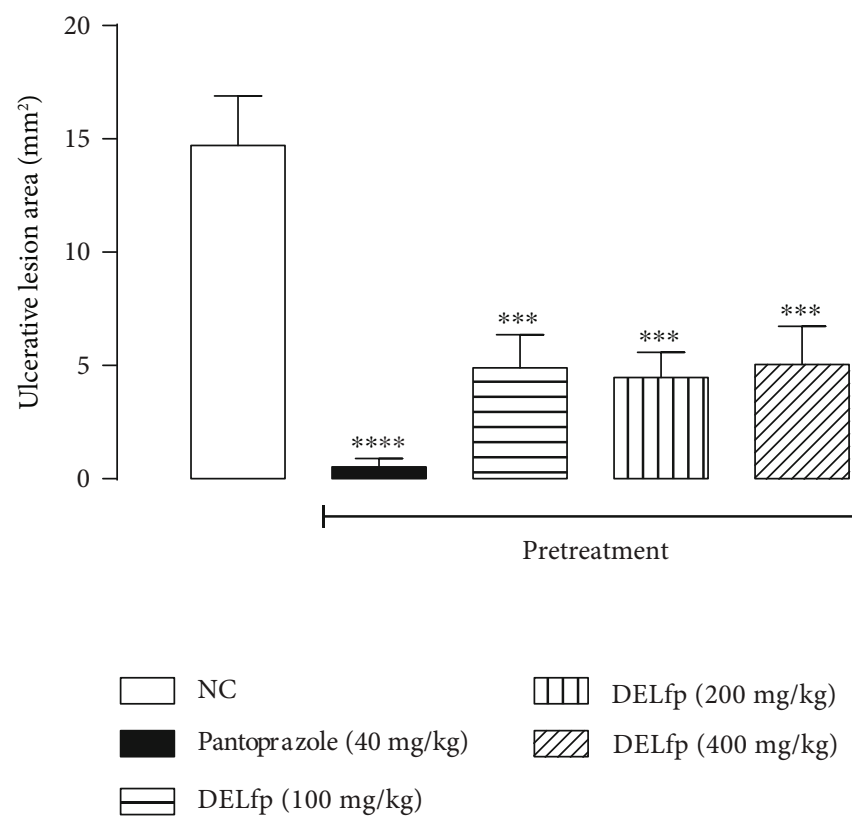

FIGURE 8: Gastroprotective effect of the dry extract of L. ferrea pods (DELfp) on indomethacin-induced gastric lesions (30 mg/kg, s.c.) in Wistar rats. Animals received, orally, $0.9 \% \mathrm{NaCl}$ (negative control, NC), pantoprazole (40 mg/kg), or DELfp (100, 200, and 400 mg/kg). Results are expressed as mean \pm SEM (6-7 animals/group). Statistically different when compared to the negative control group, ANOVA followed by Dunnett's multiple comparison test; ${ }^{* * *} p<0.001$ and ${ }^{* * * *} p<0.0001$.

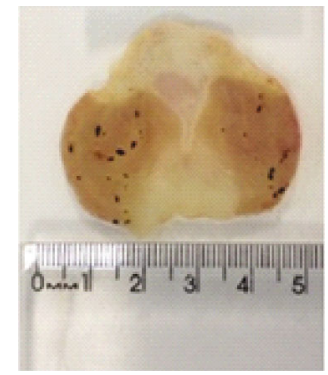

(a)

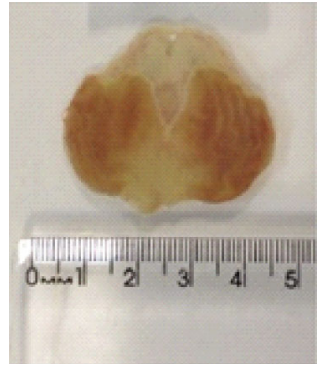

(b)

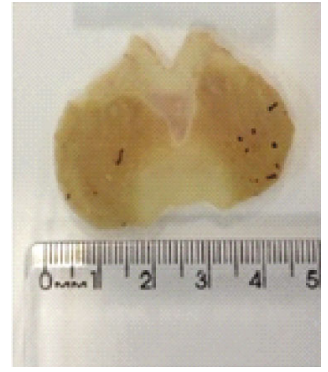

(c)

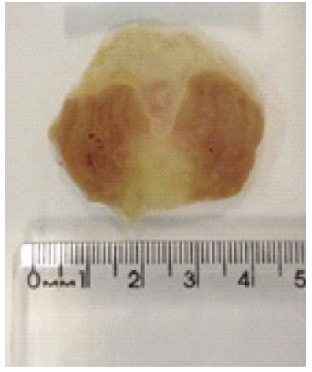

(d)

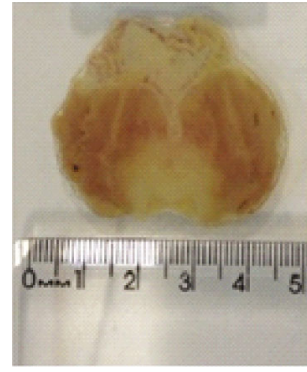

(e)

FIGURE 9: Typical photographs of the gastroprotective effect of the dry extract of $L$. ferrea pods (DELfp) on indomethacin-induced gastric lesions in Wistar rats: (a) negative control, (b) pantoprazole (40 mg/kg), and (c, d, e) DELfp (100, 200, and $400 \mathrm{mg} / \mathrm{kg}$, respectively).

GSH concentrations are physiologically elevated in gastric tissue, perhaps conferring some additional protection from the effects of gastric acid [91]. Oral administration of DELfp at the doses of 100 and $200 \mathrm{mg} / \mathrm{kg}$ significantly increased the endogenous antioxidant reserve (reduced glutathione, GSH) by $754.90 \pm 72.48$ (60.62\%) and $766.60 \pm 69.39(63.11 \%) \mathrm{nmol}$ of $\mathrm{GSH} / \mathrm{mg}$ protein, respectively, when compared to the control group $(470.00 \pm 23.75)$ (see Table 4).

Rozza et al. [92] found that the pretreatment with the hydroalcoholic extract of the leaves of Bauhinia holophylla increased GSH levels by $65.5 \%$ in the ethanol-induced gastric ulcer model, since the etiological factors of gastric ulcers are closely associated with oxidative stress and the depletion of glutathione levels in the gastric mucosa [93]. In our study, the administration of the extract, prior to ethanol, also increased the concentration of sulfhydryl compounds and suggests an antioxidant activity of $L$. ferrea that prevents the oxidative effects of ethanol and contributes to its gastroprotective activity.

3.5.1. Histopathological Analysis. In the histopathological analysis of the stomachs of the negative control group, it was possible to observe a disorganization of the simple columnar epithelium, capillary blood congestion, edema, and necrosis of the gastric mucosa (e.g., in Figure 5(a)). The pantoprazole group had a preserved gastric mucosa and glands (e.g., in Figure 5(b)).

In the DELfp group (50 and $100 \mathrm{mg} / \mathrm{kg}$ ), it was possible to verify a disorganization of the simple columnar epithelium, capillary blood congestion, edema, and necrosis of the gastric mucosa (e.g., in Figures 5(c) and 5(d)). The DELfp group $(200 \mathrm{mg} / \mathrm{kg})$ presented an unpreserved gastric mucosa, exfoliation of the simple columnar epithelium, and edema. 


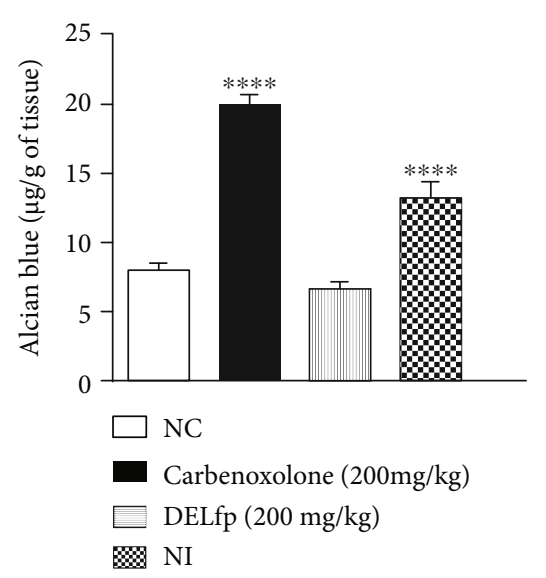

FIgURe 10: Effect of the dry extract of L. ferrea pods (DELfp) on mucus quantification. The negative control group (NC) received $0.9 \% \mathrm{NaCl}$; the positive control group received carbenoxolone $(200 \mathrm{mg} / \mathrm{kg})$, and the DELfp group received DELfp $(200 \mathrm{mg} / \mathrm{kg})$. The noninjured group (NI) received no treatment. Results are expressed as mean \pm SEM (6-8 animals/group). Statistically different when compared to the negative control group, ANOVA followed by Dunnett's multiple comparison test; ${ }^{* * * *} p<0.0001$.

Congestion of blood capillaries and necrosis were not observed (e.g., in Figure 5(e)). DELfp ( $400 \mathrm{mg} / \mathrm{kg}$ ) maintained the gastric mucus and glands preserved (e.g., in Figure 5(f)).

3.6. Acidified Ethanol- (Ethanol/HCl) Induced Ulcer. The dry extract of $L$. ferrea pods (DELfp) promoted significant protection $(200$ and $400 \mathrm{mg} / \mathrm{kg}$ ) against acidified ethanol- (ethanol/HCl) induced ulcer (see Figures 6 and 7). The results showed that animals pretreated at the doses mentioned showed inhibition of lesions of 59.12 and $96.61 \%$, respectively, compared to the negative control group (NC, 314.80 $\pm 31.23 \mathrm{~mm}^{2}$ ). The $\mathrm{ED}_{50}$ value was $185.7 \mathrm{mg} / \mathrm{kg}$. Likewise, animals treated with pantoprazole had a $58.93 \%$ reduction in the lesioned area.

Hydrochloric acid $(\mathrm{HCl})$ causes stasis in blood flow and depresses the defense mechanisms of the gastric mucosa, enhancing the action of ethanol [94]. On the other hand, ethanol is considered one of the most intense agents in the induction of gastric lesions because it promotes serious mucosal disorders due to its direct action [95, 96]. Oral administration of DELfp (200 and $400 \mathrm{mg} / \mathrm{kg}$ ) reduced etha$\mathrm{nol} / \mathrm{HCl}$-induced gastric lesions, indicating that $L$. ferrea has gastroprotective action.

3.7. Indomethacin-Induced Gastric Ulcer. Gastric lesions induced by indomethacin $(30 \mathrm{mg} / \mathrm{kg})$, a nonsteroidal antiinflammatory drug (NSAID), were significantly inhibited by DELfp $(100,200$, and $400 \mathrm{mg} / \mathrm{kg})$ at $66.72,69.64$, and $65.77 \%$, respectively, compared to the gastric lesions $\left(14.72 \pm 2.18 \mathrm{~mm}^{2}\right)$ of animals of the negative control group. In animals receiving pantoprazole, the lesioned area was inhibited by $96.40 \%$ (see Figures 8 and 9 ).

NSAID-induced gastric damages depend in part on their ability to reduce prostaglandin production by inhibiting cyclooxygenase (COX) and partly by COX-independent mechanisms [97]. The combined effects of these two mechanisms lead to marked oxidative tissue damage, which significantly contributes to gastric mucosal lesions [98].

In the stomach, prostaglandins play an important cytoprotective role because they stimulate the secretion of bicarbonate and mucus and maintain blood flow to the mucosa [97]. Hydrolyzable tannins and derivatives such as gallic acid, present in DELfp, have anti-inflammatory activity, preferentially inhibiting COX-2 [99].

Oral pretreatment with DELfp (100, 200, and $400 \mathrm{mg} / \mathrm{kg}$ ) reduced the gastric lesions caused by indomethacin, suggesting possible involvement of prostaglandins and/or mucus in the antiulcerogenic activity of the extract.

However, other mechanisms may contribute to the gastroprotective effect of DELfp. Pereira et al. [100] reported significant anti-inflammatory activity of polysaccharide fractions of $L$. ferrea pods in carrageenan-induced edema via modulation of histamine, serotonin, bradykinin, and $\mathrm{PGE}_{2}$.

3.8. Protective Factors of the Gastric Mucosa. Our results showed that the $\mathrm{ED}_{50}$ values were 113 and $185.7 \mathrm{mg} / \mathrm{kg}$, respectively, in the gastroprotection experiments (alcoholinduced and alcohol/HCl-induced ulcers). However, in the histological analysis from the ethanol-induced ulcer test, we found out that the histological parameters of the dose of $100 \mathrm{mg} / \mathrm{kg}$ (disorganization of the simple columnar epithelium in the gastric cavities, congestion of blood capillaries, necrosis of the gastric mucosa, and edema) were similar to those of the negative control, which led us to select the intermediate dose of $200 \mathrm{mg} / \mathrm{kg}$ to evaluate the possible mechanism of action. In fact, Adinortey et al. [101] have reported that the ethanol-induced ulcer model is not appropriate for the assessment of the usefulness of antisecretory drugs due to the absence of gastric secretion in this model.

3.8.1. Effect of DELfp on Gastric Mucus Production. Pyloric ligation in rats of the negative control group resulted in a significant decrease in gastric mucus levels (NC, $7.88 \pm 0.55 \mu \mathrm{g}$ Alcian blue/g tissue) compared to the noninjured group (NI, $13.35 \pm 0.95 \mu \mathrm{g}$ of Alcian blue/g tissue). Rats treated with DELfp $(200 \mathrm{mg} / \mathrm{kg})$ had no increase in mucus levels $(6.52 \pm 0.38 \mathrm{~g}$ Alcian blue/g tissue) compared to the negative control group. However, carbenoxolone $(200 \mathrm{mg} / \mathrm{kg})$ promoted a significant increase in mucus levels of $148.92 \%$ over the negative control group (see Figure 10).

Carbenoxolone maintains the prostaglandin content of the gastric mucosa at high levels due to its inhibitory action on the catabolic enzymes 15-hydroxy-prostaglandin dehydrogenase and D13-prostaglandin-reductase, in addition to increasing AMP levels by inhibition of mucosal phosphodiesterases. Carbenoxolone is a cytoprotective agent because high levels of prostaglandins promote mucosal defense against ulceration [102]. In this study, carbenoxolone increased the concentration of Alcian blue; however, this effect was not seen with DELfp. Thus, the gastroprotective effect of the extract seems to be independent of mucus participation. 
TABLE 5: Effect of the dry extract of L. ferrea pods (DELfp) on parameters of gastric secretion in Wistar rats submitted to pyloric ligation.

\begin{tabular}{lccc}
\hline Treatment & $\mathrm{pH}$ & {$\left[\mathrm{H}^{+}\right](\mathrm{mEq} / \mathrm{mL} / 4 \mathrm{~h})$} & Gastric content $(\mathrm{g})$ \\
\hline Noninjured & $4.38 \pm 0.51^{*}$ & $10.78 \pm 1.04^{* *}$ & $0.21 \pm 0.02^{* * * *}$ \\
Negative control & $3.24 \pm 0.10$ & $18.63 \pm 1.65$ & $0.74 \pm 0.08$ \\
Ranitidine $(60 \mathrm{mg} / \mathrm{kg})$ & $3.83 \pm 0.14$ & $8.39 \pm 0.89^{* * * *}$ & $0.40 \pm 0.07^{* *}$ \\
DELfp $(200 \mathrm{mg} / \mathrm{kg})$ & $3.39 \pm 0.09$ & $13.07 \pm 0.80^{*}$ & $0.35 \pm 0.05^{* *}$ \\
\hline
\end{tabular}

Values represent the mean \pm SEM (5-7 animals/group). Statistically different when compared to the negative control group, ANOVA followed by Dunnett's multiple comparison test; ${ }^{*} p<0.05,{ }^{* *} p<0.01$, and ${ }^{* * * *} p<0.0001$.

TABLE 6: Effect of oral administration of the dry extract of L. ferrea pods (DELfp) on ethanol-induced gastric lesions in Wistar rats pretreated with N-methyl-nitro-L-methyl arginine ester (L-NAME, $70 \mathrm{mg} / \mathrm{kg}$ ) or N-ethylmaleimide (NEM, $10 \mathrm{mg} / \mathrm{kg}$ ).

\begin{tabular}{|c|c|c|c|c|}
\hline Pretreatment & Treatment (p.o.) & Dose $(\mathrm{mg} / \mathrm{kg})$ & Lesion area $\left(\mathrm{mm}^{2}\right)$ & Inhibition (\%) \\
\hline \multirow{3}{*}{$0.9 \% \mathrm{NaCl}$ (i.p.) } & $\mathrm{NC}$ & - & $136.30 \pm 16.74$ & - \\
\hline & Carbenoxolone & 100 & $39.39 \pm 8.64^{*}$ & 71.11 \\
\hline & DELfp & 200 & $15.49 \pm 6.69^{* *}$ & 88.64 \\
\hline \multirow{3}{*}{ L-NAME (i.p.) } & $\mathrm{NC}$ & - & $196.30 \pm 28.11$ & - \\
\hline & Carbenoxolone & 100 & $116.30 \pm 25.24$ & 40.76 \\
\hline & DELfp & 200 & $8.66 \pm 3.33^{* * * *}$ & 95.59 \\
\hline \multirow{3}{*}{$0.9 \% \mathrm{NaCl}$ (i.p.) } & $\mathrm{NC}$ & - & $202.30 \pm 32.37$ & - \\
\hline & Carbenoxolone & 100 & $29.56 \pm 5.88^{* * *}$ & 85.39 \\
\hline & DELfp & 200 & $8.04 \pm 4.84^{* * *}$ & 96.03 \\
\hline \multirow{3}{*}{ NEM (i.p.) } & $\mathrm{NC}$ & - & $389.90 \pm 38.15$ & - \\
\hline & Carbenoxolone & 100 & $32.26 \pm 10.17^{* * * *}$ & 91.73 \\
\hline & DELfp & 200 & $399.80 \pm 50.35$ & - \\
\hline
\end{tabular}

Results are expressed as mean \pm SEM ( $n=6-8$ animals/group). NC: negative control group. Statistically different when compared to the negative control group, ANOVA followed by Dunnett's multiple comparison test; ${ }^{*} p<0.05,{ }^{* *} p<0.01,{ }^{* * *} p<0.001$, and ${ }^{* * * *} p<0.0001$.

Beserra et al. [103] found that ellagic acid (EA) alone did not have a significant effect on mucus production in stomachs of animals submitted to ulceration. This data suggests that mucus production is not involved in the gastroprotective activity of EA. The gastroprotective properties of EA were partially attributed to the inhibitory action on the proton pump $\left(\mathrm{H}^{+}, \mathrm{K}^{+}\right.$-ATPase) [104] and antioxidant properties in vivo [105]. The chromatographic analysis of DELfp showed the presence of ellagic acid and its derivatives in its composition. This may explain the noninvolvement of DELfp in the production of mucus.

3.8.2. Effect of DELfp on Gastric Acid Secretion. After $4 \mathrm{~h}$ of pyloric ligation, it was observed that intraduodenal administration of DELfp $(200 \mathrm{mg} / \mathrm{kg})$ and ranitidine $(60 \mathrm{mg} / \mathrm{kg})$ reduced gastric secretion by 52.71 and $45.95 \%$, respectively, and total acidity by 29.85 and $54.96 \%$, respectively (see Table 5).

The pyloric ligation method promotes vagovagal reflexes, increasing gastric secretion through the stimulation of mechanoreceptors present in the antral mucosa, during the pylo- rus ligation [106]. The extract of $L$. ferrea decreased the acid secretion and the concentration of $\mathrm{H}^{+}$in the gastric content. Endogenous histamine formation and release by mast cells are related to the pathogenesis of gastric ulcers produced by pylorus ligation, suggesting that antihistaminic $\left(\mathrm{H}_{2}\right)$ drugs may be useful in the prevention of lesions [107].

The results suggested that one of the mechanisms of DELfp relates to antisecretory activity and confirmed the systemic effect of the extract in the treatment of gastric ulcers, in view of the effectiveness of the treatment when the extract was administered intraduodenally.

3.8.3. Involvement of Nitric Oxide (NO) and Sulfhydryl (-SH) Compounds in Gastroprotection. N-Nitro-L-arginine methyl ester (L-NAME) and N-ethylmaleimide (NEM) exacerbated the gastric lesions induced by ethanol in 44.02 and $92.73 \%$, respectively, in relation to the effects in the groups pretreated with $\mathrm{NaCl}$ solution. DELfp $(200 \mathrm{mg} / \mathrm{kg})$ presented a gastroprotective effect in the presence of L-NAME $(70 \mathrm{mg} / \mathrm{kg}$, i.p. $)$, reducing the lesions by $95.58 \%$ compared to the blocked control group 
TABLE 7: Effect of the dry extract of $L$. ferrea pods (DELfp) on feed and water intake and body weight of rats after 14 days of treatment in the acetic acid-induced ulcer model.

\begin{tabular}{lccc}
\hline Parameter & Control $(0.9 \% \mathrm{NaCl})$ & Ranitidine $(60 \mathrm{mg} / \mathrm{kg})$ & DELfp $(200 \mathrm{mg} / \mathrm{kg})$ \\
\hline Food consumption $(\mathrm{g})$ & $287.60 \pm 1.27$ & $267.00 \pm 4.75^{* *}$ & $267.80 \pm 3.35^{* *}$ \\
Water consumption $(\mathrm{mL})$ & $512.60 \pm 10.07$ & $480.90 \pm 16.48$ & $455.40 \pm 3.70^{* *}$ \\
Initial body weight $(\mathrm{g})$ & $280.00 \pm 4.53$ & $275.70 \pm 14.21$ & $312.50 \pm 9.69$ \\
Final body weight $(\mathrm{g})$ & $312.70 \pm 3.78$ & $302.00 \pm 16.69$ & $329.50 \pm 10.03$ \\
\hline
\end{tabular}

Values represent the mean \pm SEM ( $n=6$-8/group). Statistically different when compared to the control group, ANOVA followed by Dunnett's multiple comparison test; ${ }^{* *} p<0.01$.

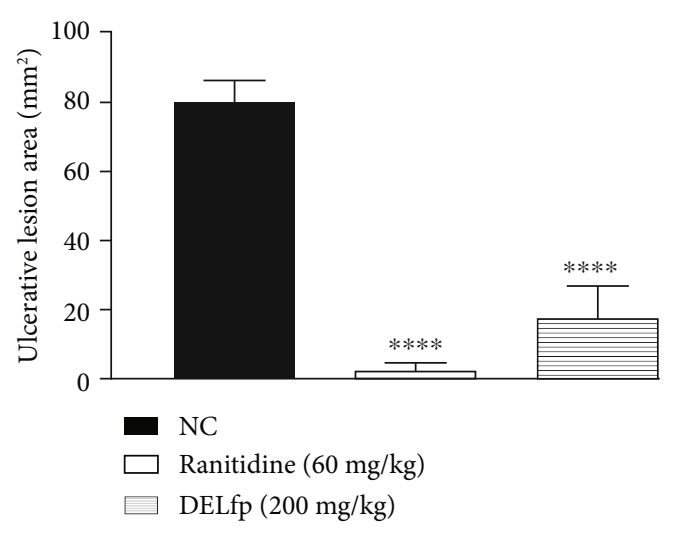

FIGURE 11: Effect of the dry extract of L. ferrea pods (DELfp) on the healing of the gastric mucosa in Wistar rats. Animals received, orally, $0.9 \% \mathrm{NaCl}$ (negative control, $\mathrm{NC}$ ), ranitidine $(60 \mathrm{mg} / \mathrm{kg})$, or DELfp $(200 \mathrm{mg} / \mathrm{kg})$. Results are expressed as mean \pm SEM $(n=6$ -8 /group). Statistically different when compared to the negative control group, ANOVA followed by Dunnett's multiple comparison test; ${ }^{* * * *} p<0.0001$.

$\left(196.30 \pm 28.11 \mathrm{~mm}^{2}\right)$. This result suggested that the gastroprotective effect of DELfp does not depend on the presence of nitric oxide (NO) (see Table 6). However, in the presence of NEM $(10 \mathrm{mg} / \mathrm{kg}$, i.p.), the gastroprotective effect of DELfp was not evident $\left(399.80 \pm 50.35 \mathrm{~mm}^{2}\right)$ when compared to the negative control group (NC, $389.90 \pm 38.15 \mathrm{~mm}^{2}$ ). Depletion of sulfhydryl compounds by pretreatment with NEM was able to eliminate the gastroprotective effect of DELfp against ulcerogenic agents. This indicates that the gastroprotective effect of DELfp depends entirely on the presence of sulfhydryl (-SH) compounds (see Table 6).

In this study, the data demonstrated that gastric exposure to ethanol associated with the depletion of sulfhydryl compounds promoted by NEM (SH inhibitor) and the inhibition of nitric oxide synthase (NOS) by L-NAME reduced gastroprotection.

Nitric oxide is considered one of the most important agents of defense of the gastric mucosa due to the increase in tissue blood flow [108]. DELfp presented compounds involved in gastroprotection, acting independently of the presence of nitric oxide but depending on the presence of sulfhydryl groups that are responsible for increasing mucus production, maintaining gastric integrity, and reducing free radical production [109].

3.9. Acetic Acid-Induced Gastric Ulcer. Our results showed that treatment with DELfp $(200 \mathrm{mg} / \mathrm{kg})$ and ranitidine $(60 \mathrm{mg} / \mathrm{kg})$ for 14 consecutive days reduced the area of chronic ulcers by 77.44 and $96.59 \%$ compared to the group treated with $0.9 \% \mathrm{NaCl}$ solution (control), in which the injured area corresponded to $79.92 \pm 6.53 \mathrm{~mm}^{2}$ (see Figures 11 and 12). It was possible to observe that DELfp showed healing activity of the gastric ulcer induced by acetic acid. The false-operated group, consisting of animals in which the ulcer was not induced, presented no lesion, as expected.

Administration of DELfp $(200 \mathrm{mg} / \mathrm{kg})$ and ranitidine $(60 \mathrm{mg} / \mathrm{kg})$ for 14 consecutive days did not cause visible signs of toxicity (diarrhea, piloerection, or changes in locomotor activity). A reduction of 6.89 and $7.17 \%$ in feed intake was observed in the animals treated with DELfp and ranitidine during 14 days (see Table 7).

Mangan [110] reported the astringent character of tannins when added to food or beverages. However, studies indicate that the major effect of tannins is not their inhibition in food consumption, but rather their decreased intestinal conversion and absorption of nutrients [111].

Oral administration of antihistamines $\left(\mathrm{H}_{2}\right)$ such as ranitidine delays gastric emptying and causes dyspeptic symptoms such as early satiety, nausea, and abdominal swelling [112]. This fact may explain the reduction of feed consumption of the animals treated with ranitidine $(60 \mathrm{mg} / \mathrm{kg})$ for 14 consecutive days in this study.

Animals treated with DELfp also had $11.16 \%$ reduced water consumption compared to the control group (see Table 8). Body weight of the animals treated with DELfp or ranitidine was similar to that of the control group.

Administration of DELfp $(200 \mathrm{mg} / \mathrm{kg})$ for 14 consecutive days resulted in $5.08 \%$ reduction $(16.44 \pm 0.24)$ in mean corpuscular hemoglobin $(\mathrm{MCH})$ compared to the control group $(17.32 \pm 0.18)$. In fact, a study conducted in our laboratory with prolonged administration (30 days) of DELfp (100 and $500 \mathrm{mg} / \mathrm{kg}$ ) showed a reduction of $7.68 \%$ and $7.30 \%$ in HCM compared to the control group (unpublished data). Hematological changes may suggest chemical stress resulting from metabolic reactions caused by toxic substances [113]. The other hematological parameters and the 


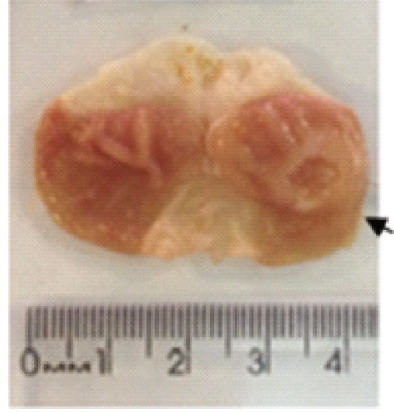

(a)

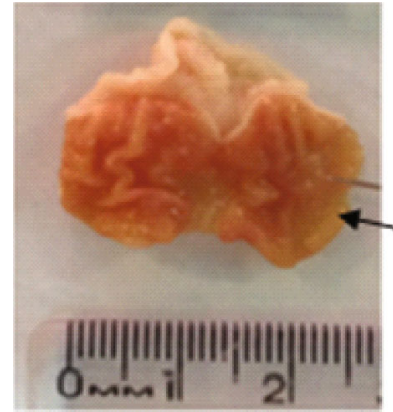

(b)

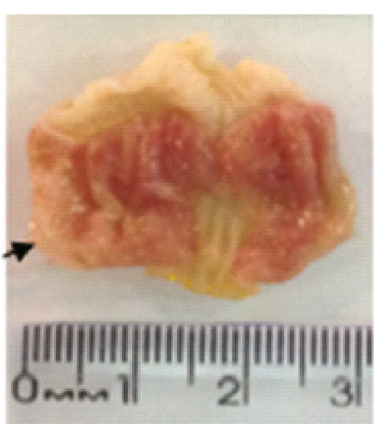

(c)

FIGURE 12: Typical photographs of the healing effect of the dry extract of L. ferrea pods (DELfp) on acetic acid-induced gastric ulcer in Wistar rats: (a) negative control group, (b) ranitidine $(60 \mathrm{mg} / \mathrm{kg})$, and (c) DELfp (200 $\mathrm{mg} / \mathrm{kg})$.

TABLE 8: Effect of the dry extract of L. ferrea pods (DELfp) on hematological and biochemical parameters in rats after 14 days of treatment in the acetic acid-induced ulcer model.

\begin{tabular}{lccc}
\hline Parameter & Control $(0.9 \% \mathrm{NaCl})$ & Ranitidine $(60 \mathrm{mg} / \mathrm{kg})$ & DELfp $(200 \mathrm{mg} / \mathrm{kg})$ \\
\hline Hematological parameter & $7.81 \pm 0.14$ & $7.28 \pm 0.48$ & $7.41 \pm 0.29$ \\
RBC (millions $\left./ \mathrm{mm}^{3}\right)$ & $12.75 \pm 0.11$ & $11.70 \pm 0.68$ & $12.09 \pm 0.54$ \\
Hb (g/dL) & $43.13 \pm 2.39$ & $40.37 \pm 2.73$ & $40.64 \pm 1.59$ \\
Ht (\%) & $54.50 \pm 0.50$ & $52.53 \pm 2.28$ & $54.88 \pm 0.29$ \\
MCV (micra $\left.{ }^{3}\right)$ & $17.32 \pm 0.18$ & $17.12 \pm 0.07$ & $16.44 \pm 0.24^{*}$ \\
MCH (pg) & $34.50 \pm 0.42$ & $34.40 \pm 0.37$ & $32.48 \pm 1.35$ \\
MCHC (\%) & $13.58 \pm 0.16$ & $14.00 \pm 0.29$ & $13.40 \pm 0.36$ \\
RDW (\%) & $952.20 \pm 39.24$ & $1020.00 \pm 45.51$ & $924.60 \pm 17.58$ \\
Platelets (mm $\left.{ }^{3}\right)$ & & & $0.81 \pm 0.02$ \\
Biochemical parameter & $0.78 \pm 0.03$ & $0.66 \pm 0.04$ & $43.13 \pm 1.48$ \\
Creatinine (mg/dL) & $42.67 \pm 2.97$ & $45.67 \pm 1.47$ & $144.60 \pm 11.57$ \\
BUN (mg/dL) & $230.50 \pm 69.72$ & $168.70 \pm 25.20$ & $129.40 \pm 5.78$ \\
ALP (U/L) & $129.00 \pm 14.06$ & $168.00 \pm 10.00$ & $43.88 \pm 2.83$ \\
AST (U/L) & $51.00 \pm 5.93$ & $51.00 \pm 3.05$ & \\
ALT (U/L) & & & \\
\hline
\end{tabular}

RBC: red blood cell; Hb: hemoglobin; Ht: hematocrit; MCV: mean corpuscular volume; MCH: mean corpuscular hemoglobin; MCHC: mean corpuscular hemoglobin concentration; RDW: red cell distribution width; ALP: alkaline phosphatase; AST: aspartate aminotransferase; ALT: alanine aminotransferase; BUN: blood urea nitrogen. Values represent the mean \pm SEM ( $n=6-8$ /group). Statistically different when compared to the control group, ANOVA followed by Dunnett's multiple comparison test; ${ }^{*} p<0.05$.

biochemical parameters evaluated were not affected by DELfp (see Table 8).

3.9.1. Histological Analysis. In the histological analysis of the stomachs, sections fixed and stained with H\&E and Masson's trichrome (TM) revealed well-defined ulcers with destruction of the mucosa and submucosa layer caused by acetic acid in animals of the control group. Stomachs of rats orally treated with DELfp $(200 \mathrm{mg} / \mathrm{kg})$ and ranitidine $(60 \mathrm{mg} / \mathrm{kg})$ presented similar tissue regeneration to those in the negative control group (see Figure 13).

3.10. Helicobacter pylori. The MIC of the extract was evaluated and, by definition, represents the concentration where at least $90 \%$ inhibition of bacterial growth was obtained.
DELfp showed anti-H. pylori activity with MIC of $512 \mu \mathrm{g} / \mathrm{mL}$. Amoxicillin had an MIC of $0.3125 \mu \mathrm{g} / \mathrm{mL}$. In turn, MBC corresponded to the concentration where bacterial colonies were not observed. In this assay, the DELfp presented MBC of $512 \mu \mathrm{g} / \mathrm{mL}$.

The ethanolic extract of Spondias mombin, rich in gallic acid and ellagic acid, showed anti-H. pylori activity with MIC of $256 \mu \mathrm{g} / \mathrm{mL}$ [62]. Other studies have demonstrated antibacterial activity of $L$. ferrea stem bark extracts against other bacterial strains such as Staphylococcus aureus [29, 100]. Baydar et al. [114] and Tomás-Menor et al. [115] showed that the antibacterial activity of plant species is proportional to the amount of phenolic compounds in the plant. 


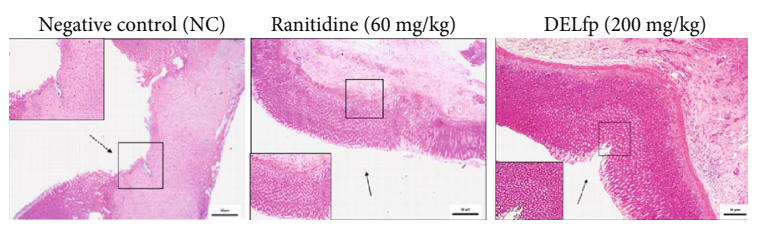

(a)

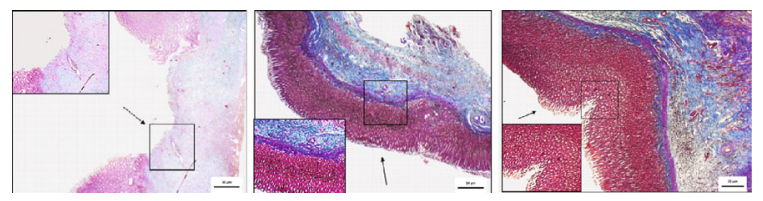

(b)

FIGURE 13: Photomicrographs of the gastric mucosa stained with hematoxylin/eosin (a) and Masson's trichrome (b) of rats submitted to induction of chronic ulcer by $30 \%$ acetic acid. The animals were treated orally with $0.9 \% \mathrm{NaCl}$ solution (negative control, NC), ranitidine $(60 \mathrm{mg} / \mathrm{kg})$, or dry extract of $L$. ferrea pods (DELfp, $200 \mathrm{mg} / \mathrm{kg}$ ) for 14 days. The filled arrow indicates the absence of ulcer and/or preserved columnar simple epithelium or reepithelialisation, and the dashed arrow indicates the presence of ulcer, lymphoplasmacytic infiltrate, and destruction of the mucosa.

Helicobacter pylori infection induces inflammation, causing damage that is partly attributable to ROS production. The infection overwhelms the ability of mucosal cells and local glutathione to prevent ROS-mediated damage. Therapeutic regulation of glutathione availability prevents damage caused by $H$. pylori [91]. DELfp increased GSH levels in the gastric mucosa in ethanol-induced lesions, thus presenting potential to reduce $H$. pylori damage in the production of lesions.

\section{Conclusions}

DELfp showed gastroprotective, antiulcerogenic, and gastric healing activity mediated by antioxidant and antisecretory activity and the involvement of sulfhydryl compounds in addition to anti-H. pylori effect. These mechanisms may contribute to the healing of chronic ulcers, promoted by the dry extract of pods of $L$. ferrea. These data validate its use in folk medicine.

\section{Data Availability}

We, the authors, support and endorse the FAIR Guiding Principles for scientific data management and stewardship-findability, accessibility, interoperability, and reusability. The experimental data used to support the findings of this study are included within the manuscript. However, additional information from this study may be obtained upon request to the corresponding author (almir.wanderley@ufpe.br or almirgw.wanderley@gmail.com). We ensured that Hindawi (Oxidative Medicine and Cellular Longevity) has the rights necessary for the proper administration of electronic rights and online dissemination of the manuscript entitled "Antioxidant and Antiulcerogenic Activity of the Dry Extract of Pods of Libidibia ferrea Mart. ex Tul. (Fabaceae)."

\section{Conflicts of Interest}

The authors declare that there is no conflict of interest regarding the publication of this article.

\section{Acknowledgments}

We thank Norberto Peporine Lopes from the Center for Mass Spectrometry of Organic Micromolecules (CEMMO) of the Faculty of Pharmaceutical Sciences of the University of São Paulo (Ribeirão Preto) for allowing us to use LC-MS. This research was funded by FACEPE (IBPG-0383-4.03/15).

\section{References}

[1] A. Lanas and F. K. L. Chan, "Peptic ulcer disease," The Lancet, vol. 390, no. 10094, pp. 613-624, 2017.

[2] V. K. Bansal, S. K. Goyal, D. S. Goswami, S. Singla, S. Rahar, and S. Kumar, "Herbal approach to peptic ulcer disease review," Journal Bioscience Technology, vol. 1, no. 1, pp. 5258,2009 .

[3] K. S. de Lira Mota, G. E. N. Dias, M. E. F. Pinto et al., "Flavonoids with gastroprotective activity," Molecules, vol. 14, no. 3, pp. 979-1012, 2009.

[4] B. Sivri, "Trends in peptic ulcer pharmacotherapy," Fundamental \& Clinical Pharmacology, vol. 18, no. 1, pp. 23-31, 2004.

[5] M. J. O. E. Bertleff and J. F. Lange, "Perforated peptic ulcer disease: a review of history and treatment," Digestive Surgery, vol. 27, no. 3, pp. 161-169, 2010.

[6] J. Y. Lau, J. Sung, C. Hill, C. Henderson, C. W. Howden, and D. C. Metz, "Systematic review of the epidemiology of complicated peptic ulcer disease: incidence, recurrence, risk factors and mortality," Digestion, vol. 84, no. 2, pp. 102-113, 2011.

[7] K. Thorsen, J. A. Søreide, J. T. Kvaløy, T. Glomsaker, and K. Søreide, "Epidemiology of perforated peptic ulcer: ageand gender-adjusted analysis of incidence and mortality," World Journal of Gastroenterology, vol. 19, no. 3, pp. 347354, 2013.

[8] L. J. de Lacerda Neto, A. G. B. Ramos, V. S. Sales et al., "Gastroprotective and ulcer healing effects of hydroethanolic extract of leaves of Caryocar coriaceum : Mechanisms involved in the gastroprotective activity," Chemico-Biological Interactions, vol. 261, pp. 56-62, 2017.

[9] M. Kalayci, M. A. Kocdor, T. Kuloglu et al., "Comparison of the therapeutic effects of sildenafil citrate, heparin and neuropeptides in a rat model of acetic acid-induced gastric ulcer," Life Sciences, vol. 186, pp. 102-110, 2017.

[10] S. B. Manjegowda, H. M. Rajagopal, and S. M. Dharmesh, "Polysaccharide of black cumin (Nigella sativa) modulates molecular signaling cascade of gastric ulcer pathogenesis," International Journal of Biological Macromolecules, vol. 101, pp. 823-836, 2017.

[11] J. M. Matés, "Effects of antioxidant enzymes in the molecular control of reactive oxygen species toxicology," Toxicology, vol. 153, no. 1-3, pp. 83-104, 2000.

[12] R. Rao, R. D. Baker, and S. S. Baker, "Inhibition of oxidant-induced barrier disruption and protein tyrosine phosphorylation in Caco-2 cell monolayers by epidermal 
growth factor," Biochemical Pharmacology, vol. 57, no. 6, pp. 685-695, 1999.

[13] A. Bhattacharyya, R. Chattopadhyay, S. Mitra, and S. E. Crowe, "Oxidative stress: an essential factor in the pathogenesis of gastrointestinal mucosal diseases," Physiological Reviews, vol. 94, no. 2, pp. 329-354, 2014.

[14] A. E. Bighetti, M. A. Antônio, L. K. Kohn et al., "Antiulcerogenic activity of a crude hydroalcoholic extract and coumarin isolated from Mikania laevigata Schultz Bip," Phytomedicine, vol. 12, no. 1-2, pp. 72-77, 2005.

[15] S. B. Almasaudi, N. A. El-Shitany, A. T. Abbas et al., "Antioxidant, anti-inflammatory, and antiulcer potential of manuka honey against gastric ulcer in rats," Oxidative Medicine and Cellular Longevity, vol. 2016, Article ID 3643824, 10 pages, 2016.

[16] A. B. R. Thomson, M. D. Sauve, N. Kassam, and H. Kamitakahara, "Safety of the long-term use of proton pump inhibitors," World Journal of Gastroenterology, vol. 16, no. 19, pp. 2323-2330, 2010.

[17] N. Kangwan, J.-M. Park, E.-H. Kim, and K. B. Hahm, "Quality of healing of gastric ulcers: natural products beyond acid suppression," World Journal of Gastrointestinal Pathophysiology, vol. 5, no. 1, pp. 40-47, 2014.

[18] M. J. S. Langman, "Ulcer complications associated with antiinflammatory drug use. What is the extent of the disease burden?," Pharmacoepidemiology and Drug Safety, vol. 10, no. 1, pp. 13-19, 2001.

[19] W. A. Carvalho, R. D. S. Carvalho, and F. Rios-Santos, "Specific cyclooxygenase-2 inhibitor analgesics: therapeutic advances," Revista Brasileira de Anestesiologia, vol. 54, no. 3, pp. 448-464, 2004.

[20] J. R. Warren and B. Marshall, "Unidentified curved bacilli on gastric epithelium in active chronic gastritis," The Lancet, vol. 321, no. 8336, pp. 1273-1275, 1983.

[21] S. K. Tiwari, A. A. Khan, K. S. Ahmed et al., "Rapid diagnosis of Helicobacter pylori infection in dyspeptic patients using salivary secretion: a non-invasive approach," Singapore Medical Journal, vol. 46, no. 5, pp. 224-228, 2005.

[22] K. Alam, T. T. Schubert, S. D. Bologna, and C. K. Ma, "Increased density of Helicobacter pylori on antral biopsy is associated with severity of acute and chronic inflammation and likelihood of duodenal ulceration," American Journal of Gastroenterology, vol. 87, no. 4, pp. 424-428, 1992.

[23] S. Khulusi, M. A. Mendall, P. Patel, J. Levy, S. Badve, and T. C. Northfield, "Helicobacter pylori infection density and gastric inflammation in duodenal ulcer and non-ulcer subjects," Gut, vol. 37, no. 3, pp. 319-324, 1995.

[24] H. Lorenzi, Brazilian Trees: a manual for identification and cultivation of native tree plants in Brazil, Editora: Instituto Plantarum de Estudos da Flora, 2a edition, 2002.

[25] F. J. A. Matos, "Medicinal plants: guide for the selection and use of plants used in phytotherapy in Northeastern Brazil," Editora: UFC Edições, $3^{\text {a }}$ edition, 2007.

[26] C. F. B. Vasconcelos, H. M. L. Maranhão, T. M. Batista et al., "Hypoglycaemic activity and molecular mechanisms of Caesalpinia ferrea Martius bark extract on streptozotocininduced diabetes in Wistar rats," Journal of Ethnopharmacology, vol. 137, no. 3, pp. 1533-1541, 2011.

[27] F. C. Sampaio, M. S. V. Pereira, C. S. Dias, V. C. O. Costa, N. C. O. Conde, and M. A. R. Buzalaf, "In vitro antimicrobial activity of Caesalpinia ferrea Martius fruits against oral path- ogens," Journal of Ethnopharmacology, vol. 124, no. 2, pp. 289-294, 2009.

[28] J. C. T. Carvalho, J. R. M. Teixeira, P. J. C. Souza, J. K. Bastos, D. S. Filho, and S. J. Sarti, "Preliminary studies of analgesic and anti-inflammatory properties of Caesalpinia ferrea crude extract," Journal of Ethnopharmacology, vol. 53, no. 3, pp. 175-178, 1996.

[29] A. A. de Araújo, L. A. L. Soares, M. R. A. Ferreira et al., "Quantification of polyphenols and evaluation of antimicrobial, analgesic and anti-inflammatory activities of aqueous and acetone-water extracts of Libidibia ferrea, Parapiptadenia rigida and Psidium guajava," Journal of Ethnopharmacology, vol. 156, pp. 88-96, 2014.

[30] S. M. A. Lima, L. C. C. Araújo, M. M. Sitônio et al., "Antiinflammatory and analgesic potential of Caesalpinia ferrea," Revista Brasileira de Farmacognosia, vol. 22, no. 1, pp. 169175, 2012.

[31] I. A. C. Menezes, I. J. A. Moreira, A. A. Carvalho, A. R. Antoniolli, and M. R. V. Santos, "Cardiovascular effects of the aqueous extract from Caesalpinia ferrea : Involvement of ATP-sensitive potassium channels," Vascular Pharmacology, vol. 47, no. 1, pp. 41-47, 2007.

[32] A. C. V. A. Guerra, L. A. L. Soares, M. R. A. Ferreira et al., "Libidibia ferrea presents antiproliferative, apoptotic and antioxidant effects in a colorectal cancer cell line," Biomedicine \& Pharmacoterapy, vol. 92, pp. 696-706, 2017.

[33] H.-B. Li, C.-C. Wong, K.-W. Cheng, and F. Chen, "Antioxidant properties in vitro and total phenolic contents in methanol extracts from medicinal plants," LWT - Food Science and Technology, vol. 41, no. 3, pp. 385-390, 2008.

[34] R. G. Woisky and A. Salatino, "Analysis of Propolis: some parameters and procedures for chemical quality control," Journal of Apicultural Research, vol. 37, no. 2, pp. 99-105, 1998.

[35] A. D. A. Uchôa, W. F. Oliveira, A. P. C. Pereira et al., "Antioxidant activity and phytochemical profile of Spondias tuberosa Arruda leaves extracts leaves," American Journal of Plant Sciences, vol. 6, no. 19, pp. 3038-3044, 2015.

[36] W. Brand-Williams, M. E. Cuvelier, and C. Berset, "Use of a free radical method to evaluate antioxidant activity," LWT - Food Science and Technology, vol. 28, no. 1, pp. 25-30, 1995.

[37] P. Prieto, M. Pineda, and M. Aguilar, "Spectrophotometric quantification of antioxidant capacity through the formation of a phosphomolybdenum complex: specific application to the determination of vitamin E," Analytical Biochemistry, vol. 269, no. 2, pp. 337-341, 1999.

[38] N. Dasgupta and B. De, "Antioxidant activity of Piper betle L. leaf extract in vitro," Food Chemistry, vol. 88, no. 2, pp. 219224, 2004.

[39] Organisation for Economic Cooperation and Development (OECD), OECD Guideline for Testing of Chemicals. Guidance $N^{\circ}$. 425. Acute Oral Toxicity-Up-and-Down Procedure, Adopted 17 December 2001December 2018, http://www .oecd.org/chemicalsafety/risk-assessment/1948378.pdf.

[40] A. Robert, J. E. Nezamis, C. Lancaster, and A. J. Hanchar, "Cytoprotection by prostaglandins in rats. Prevention of gastric necrosis produced by alcohol, $\mathrm{HCl}, \mathrm{NaOH}$, hypertonic $\mathrm{NaCl}$ and thermal injury," Gastroenterology, vol. 77, no. 3, pp. 433-443, 1979. 
[41] H. Ohkawa, N. Ohishi, and K. Yagi, "Assay for lipid peroxides in animal tissues by thiobarbituric acid reaction," Analytical Biochemistry, vol. 95, no. 2, pp. 351-358, 1979.

[42] J. Sedlak and R. H. Lindsay, "Estimation of total, proteinbound, and nonprotein sulfhydryl groups in tissue with Ellman's reagent," Analytical Biochemistry, vol. 25, no. 1, pp. 192-205, 1968.

[43] T. Mizui and M. Doteuchi, "Effect of polyamines on acidified ethanol-induced gastric lesions in rats," The Japanese Journal Pharmacology, vol. 33, no. 5, pp. 939-945, 1983.

[44] B. Djahanguiri, "The production of acute gastric ulceration by indomethacin in the rat," Scandinavian Journal of Gastroenterology, vol. 4, no. 3, pp. 265-267, 1969.

[45] S. J. Corne, S. M. Morrissey, and R. J. Woods, "Proceedings: a method for the quantitative estimation of gastric barrier mucus," Journal of Physiology, vol. 242, no. 2, pp. 116-117, 1974.

[46] S. Rafatullah, M. Tariq, M. A. Al-Yahya, J. S. Mossa, and A. M. Ageel, "Evaluation of turmeric (Curcuma longa) for gastric and duodenal antiulcer activity in rats," Journal of Ethnopharmacology, vol. 29, no. 1, pp. 25-34, 1990.

[47] H. Shay, S. A. Komarov, S. S. Fels, and D. Meranze, “A simple method for the uniform production of gastric ulceration in the rat," Gastroenterology, vol. 5, pp. 43-61, 1945.

[48] J. Arrieta, J. Benitez, E. Flores, C. Castillo, and A. Navarrete, "Purification of gastroprotective triterpenoids from the stem bark of Amphipterygium adstringens; role of prostaglandins, sulfhydryls, nitric oxide and capsaicin-sensitive neurons," Planta Medica, vol. 69, no. 10, pp. 905-909, 2003.

[49] H. Matsuda, Y. Li, and M. Yoshikawa, "Roles of capsaicinsensitive sensory nerves, endogenous nitric oxide, sulphydryls, and prostaglandins in gastroprotection by momordin Ic, an oleanolic acid oligoglycoside, on ethanol-induced gastric mucosal lesions in rats," Life Sciences, vol. 65, no. 2, pp. 27-32, 1999.

[50] K. Takagi, S. Okabe, and R. Saziki, "A new method for the production of chronic gastric ulcer in rats and the effect of several drugs on its healing," Japanese Journal of Pharmacology, vol. 19, no. 3, pp. 418-426, 1969.

[51] CLSI, "Methods for Dilution Antimicrobial Susceptibility Tests for Bacteria That Grow Aerobically," Clinical and Laboratory Standards Institute, vol. M07-A10, pp. 1-87, 2015.

[52] CLSI, "Performance standards for antimicrobial susceptibility testing," Clinical and Laboratory Standards Institute, vol. M100, pp. 1-250, 2017.

[53] C. C. Wyrepkowski, D. L. M. G. Costa, A. P. Sinhorin et al., "Characterization and quantification of the compounds of the ethanolic extract from Caesalpinia ferrea stem bark and evaluation of their mutagenic activity," Molecules, vol. 19, no. 10, pp. 16039-16057, 2014.

[54] U. A. Fischer, R. Carle, and D. R. Kammerer, "Identification and quantification of phenolic compounds from pomegranate (Punica granatum L.) peel, mesocarp, aril and differently produced juices by HPLC-DAD-ESI/MSn," Food Chemistry, vol. 127, no. 2, pp. 807-821, 2011.

[55] S. A. O. Santos, J. J. Villaverde, A. F. Sousa, J. F. J. Coelho, C. P. Neto, and A. J. D. Silvestre, "Phenolic composition and antioxidant activity of industrial cork by-products," Industrial Crops and Products, vol. 47, pp. 262-269, 2013.

[56] J. Sun, F. Liang, Y. Bin, P. Li, and C. Duan, "Screening noncolored phenolics in red wines using liquid chromatogra- phy/ultraviolet and mass spectrometry/mass spectrometry libraries," Molecules, vol. 12, no. 3, pp. 679-693, 2007.

[57] W. Mullen, T. Yokota, M. E. J. Lean, and A. Crozier, “Analysis of ellagitannins and conjugates of ellagic acid and quercetin in raspberry fruits by LC-MS ${ }^{\mathrm{n}}$," Phytochemistry, vol. 64, no. 2, pp. 617-624, 2003.

[58] I. M. Abu-Reidah, M. S. Ali-Shtayeh, R. M. Jamous, D. Arráez-Román, and A. Segura-Carretero, "HPLC-DADESI-MS/MS screening of bioactive components from Rhus coriaria L. (Sumac) fruits," Food Chemistry, vol. 166, pp. 179-191, 2015.

[59] M. N. Clifford and A. Scalbert, "Ellagitannins - nature, occurrence and dietary burden," Journal of the Science of Food and Agriculture, vol. 80, no. 7, pp. 1118-1125, 2000.

[60] Y.-Y. Soong and P. J. Barlow, "Quantification of gallic acid and ellagic acid from longan (Dimocarpus longan Lour.) seed and mango (Mangifera indica L.) kernel and their effects on antioxidant activity," Food Chemistry, vol. 97, no. 3, pp. 524-530, 2006.

[61] H. R. Silva, C. C. M. da Silva, L. B. Caland Neto, J. A. D. Lopes, A. M. G. L. Citó, and M. H. Chaves, "Chemical constituents of Cenostigma macrophyllum stem bark: occurrence of cholesterol," Química Nova, vol. 30, no. 8, pp. 1877-1881, 2007.

[62] S. A. Brito, C. L. F. de Almeida, T. I. de Santana et al., "Antiulcer activity and potential mechanism of action of the leaves of Spondias mombin L," Oxidative Medicine and Cellular Longevity, vol. 2018, Article ID 1731459, 20 pages, 2018.

[63] R. Kaur, S. Arora, and B. Singh, "Antioxidant activity of the phenol rich fractions of leaves of Chukrasia tabularis A. Juss," Bioresource Technology, vol. 99, no. 16, pp. 7692-7698, 2008.

[64] L. C. N. da Silva, C. A. da Silva, R. M. de Souza, A. J. Macedo, M. V. da Silva, and M. T. dos Santos Correia, "Comparative analysis of the antioxidant and DNA protection capacities of Anadenanthera colubrina, Libidibia ferrea and Pityrocarpa moniliformis fruits," Food and Chemical Toxicology, vol. 49, no. 9, pp. 2222-2228, 2011.

[65] P. S. Port's, R. C. Chisté, H. T. Godoy, and M. A. Prado, “The phenolic compounds and the antioxidant potential of infusion of herbs from the Brazilian Amazonian region," Food Research International, vol. 53, no. 2, pp. 875-881, 2013.

[66] K. E. Heim, A. R. Tagliaferro, and D. J. Bobilya, "Flavonoid antioxidants: chemistry, metabolism and structure-activity relationships," Journal of Nutritional Biochemistry, vol. 13, no. 10, pp. 572-584, 2002.

[67] M. L. F. Ferreyra, S. P. Rius, and P. Casati, "Flavonoids: biosynthesis, biological functions, and biotechnological applications," Frontiers in Plant Science, vol. 3, article 222, 2012.

[68] N. A. Hayes and J. C. Foreman, "The activity of compounds extracted from feverfew on histamine release from rat mast cells," Journal of Pharmacy and Pharmacology, vol. 39, no. 6, pp. 466-470, 1987.

[69] A. A. Izzo, G. Di Carlo, N. Mascolo, and F. Capasso, "Antiulcer effect of flavonoids. Role of endogenous PAF," Phytotherapy Research, vol. 8, no. 3, pp. 179-181, 1994.

[70] A. C. Rosam, J. L. Wallace, and B. J. R. Whittle, "Potent ulcerogenic actions of platelet-activating factor on the stomach," Nature, vol. 319, no. 6048, pp. 54-56, 1986.

[71] J. L. Wallace and B. J. R. Whittle, "Profile of gastrointestinal damage induced by platelet-activating factor," Prostaglandins, vol. 32, no. 1, pp. 137-141, 1986. 
[72] A. O. Barros, R. S. Souza, E. S. P. Aranha et al., "Antioxidant and hepatoprotective activities of Libidibia ferrea bark and fruit extracts," International Journal of Pharmacy and Pharmaceutical Sciences, vol. 6, no. 11, pp. 71-76, 2014.

[73] P. M. L. Santos, A. S. Japp, L. G. Lima, J. Schripsema, F. de Sousa Menezes, and R. M. Kuster, "Antioxidant activity from the leaf extracts of Jacaranda puberula Cham., Bignoniaceae, a Brazilian medicinal plant used for blood depuration," Revista Brasileira de Farmacognosia, vol. 20, no. 2, pp. 147153, 2010.

[74] A. Rebaya, S. I. Belghith, B. Baghdikian et al., "Total phenolic, total flavonoid, tannin content, and antioxidant capacity of Halimium halimifolium (Cistaceae)," Journal of Applied Pharmaceutical Science, vol. 5, no. 1, pp. 52-57, 2014.

[75] R. L. Prior, X. Wu, and K. Schaich, "Standardized methods for the determination of antioxidant capacity and phenolics in foods and dietary supplements," Journal of Agricultural and Food Chemistry, vol. 53, no. 10, pp. 4290-4302, 2005.

[76] S. K. Hassan, N. M. El-Sammad, A. M. Mousa et al., "Hypoglycemic and antioxidant activities of Caesalpinia ferrea Martius leaf extract in streptozotocin-induced diabetic rats," Asian Pacific Journal of Tropical Biomedicine, vol. 5, no. 6, pp. 462-471, 2015.

[77] S. Shukla, A. Mehta, J. John, S. Singh, P. Mehta, and S. P. Vyas, "Antioxidant activity and total phenolic content of ethanolic extract of Caesalpinia bonducella seeds," Food and Chemical Toxicology, vol. 47, no. 8, pp. 1848-1851, 2009.

[78] A. C. C. Freitas, N. C. A. Ximenes, J. S. Aguiar et al., "Biological activities of Libidibia (Caesalpinea) ferrea var. parvifolia (Mart. ex Tul.) L. P. Queiroz pod preparations," EvidenceBased Complementary and Alternative Medicine, vol. 2012, Article ID 514134, 7 pages, 2012.

[79] Y. T. S. Kobayashi, V. T. Almeida, T. Bandeira, and B. N. de Alcántara, "Phytochemical evaluation and wound healing potential of the fruit extract ethanolic of jucá (Libidibia ferrea) in wistar rats," Brazilian Journal of Veterinary Research and Animal Science, vol. 52, no. 1, pp. 34-40, 2015.

[80] C. Rujjanawate, D. Kanjanapothi, D. Amornlerdpison, and S. Pojanagaroon, "Anti-gastric ulcer effect of Kaempferia parviflora," Journal of Ethnopharmacology, vol. 102, no. 1, pp. 120-122, 2005.

[81] M. G. Repetto and S. F. Llesuy, "Antioxidant properties of natural compounds used in popular medicine for gastric ulcers," Brazilian Journal of Medical and Biological Research, vol. 35, no. 5, pp. 523-534, 2002.

[82] S. Kwiecien, T. Brzozowski, and S. J. Konturek, "Effects of reactive oxygen species action on gastric mucosa in various models of mucosal injury," Journal of Physiology and Pharmacology, vol. 53, no. 1, pp. 39-50, 2002.

[83] A. Franke, S. Teyssen, and M. V. Singer, "Alcohol-related diseases of the esophagus and stomach," Digestive Diseases, vol. 23, no. 3-4, pp. 204-213, 2005.

[84] A. S. Tarnawski, "Cellular and molecular mechanisms of gastrointestinal ulcer healing," Digestive Diseases and Sciences, vol. 50, no. 1, pp. 24-33, 2005.

[85] A. Tarnawski, A. Ahluwalia, and M. K. Jones, "Gastric cytoprotection beyond prostaglandins: cellular and molecular mechanisms of gastroprotective and ulcer healing actions of antacids," Current Pharmaceutical Design, vol. 19, no. 1, pp. 126-132, 2013.
[86] O. M. E. Abdel-Salam, J. Czimmer, A. Debreceni, J. Szolcsányi, and G. Mózsik, "Gastric mucosal integrity: gastric mucosal blood flow and microcirculation. An overview," Journal of Physiology, vol. 95, no. 1-6, pp. 105-127, 2001.

[87] D. Bagchi, O. R. Carryl, M. X. Tran et al., "Stress, diet and alcohol-induced oxidative gastrointestinal mucosal injury in rats and protection by bismuth subsalicylate," Journal of Applied Toxicology, vol. 18, no. 1, pp. 3-13, 1998.

[88] D. Del Rio, A. J. Stewart, and N. Pellegrini, "A review of recent studies on malondialdehyde as toxic molecule and biological marker of oxidative stress," Nutrition, Metabolism and Cardiovascular Diseases, vol. 15, no. 4, pp. 316-328, 2005.

[89] J. Fernández, J. A. Pérez-Álvarez, and J. A. Fernández-López, "Thiobarbituric acid test for monitoring lipid oxidation in meat," Food Chemistry, vol. 59, no. 3, pp. 345-353, 1997.

[90] G. F. R. Caldas, I. M. do Amaral Costa, J. B. R. da Silva et al., "Antiulcerogenic activity of the essential oil of Hyptis martiusii Benth. (Lamiaceae)," Journal of Ethnopharmacology, vol. 137, no. 1, pp. 886-892, 2011.

[91] G. M. Matthews and R. N. Butler, "Cellular mucosal defense during Helicobacter pylori infection: a review of the role of glutathione and the oxidative pentose pathway," Helicobacter, vol. 10, no. 4, pp. 298-306, 2005.

[92] A. L. Rozza, D. A. S. Cesar, L. G. Pieroni et al., "Antiulcerogenic activity and toxicity of Bauhinia holophylla hydroalcoholic extract," Evidence-Based Complementary and Alternative Medicine, vol. 2015, Article ID 439506, 9 pages, 2015.

[93] M. Jozefczak, T. Remans, J. Vangronsveld, and A. Cuypers, "Glutathione is a key player in metal-induced oxidative stress defenses," International Journal of Molecular Sciences, vol. 13, no. 3, pp. 3145-3175, 2012.

[94] M. A. Andreo, K. V. R. Ballesteros, C. A. Hiruma-Lima, L. R. M. da Rocha, A. R. M. S. Brito, and W. Vilegas, "Effect of Mouriri pusa extracts on experimentally induced gastric lesions in rodents: Role of endogenous sulfhydryls compounds and nitric oxide in gastroprotection," Journal of Ethnopharmacology, vol. 107, no. 3, pp. 431-441, 2006.

[95] S. Szabo, J. S. Trier, A. Brown, J. Schnoor, H. D. Homan, and J. C. Bradford, "A quantitative method for assessing the extent of experimental gastric erosions and ulcers," Journal of Pharmacological Methods, vol. 13, no. 1, pp. 59-66, 1985.

[96] C. A. Hiruma-Lima, L. M. Batista, A. B. A. de Almeida et al., "Antiulcerogenic action of ethanolic extract of the resin from Virola surinamensis Warb. (Myristicaceae)," Journal of Ethnopharmacology, vol. 122, no. 2, pp. 406-409, 2009.

[97] J. L. Wallace, "Prostaglandins, NSAIDs, and gastric mucosal protection: why doesn't the stomach digest itself?," Physiological Reviews, vol. 88, no. 4, pp. 1547-1565, 2008.

[98] H. Hiraishi, T. Shimada, and A. Terano, "Involvement of oxidative stress in the pathogenesis of NSAID-induced gastric mucosal damage," Journal of Gastroenterology, vol. 35, no. 7, pp. 567-569, 2000.

[99] S.-J. Lee, I.-S. Lee, and W. Mar, "Inhibition of inducible nitric oxide synthase and cyclooxygenase- 2 activity by 1,2,3,4,6penta-O-galloyl- $\beta$-D-glucose in murine macrophage cells," Archives of Pharmacal Research, vol. 26, no. 10, pp. 832839, 2003.

[100] L. de Paulo Pereira, R. O. da Silva, P. H. de Souza Ferreira Bringel, K. E. S. da Silva, A. M. S. Assreuy, and M. G. Pereira, "Polysaccharide fractions of Caesalpinia ferrea pods: 
potential anti-inflammatory usage," Journal of Ethnopharmacology, vol. 139, no. 2, pp. 642-648, 2012.

[101] M. B. Adinortey, C. Ansah, I. Galyuon, and A. Nyarko, "In vivo models used for evaluation of potential antigastroduodenal ulcer agents," Ulcers, vol. 2013, Article ID 796405, 12 pages, 2013.

[102] D. A. Lewis and P. J. Hanson, "Anti-ulcer drugs of plant origin," Progress in Medicinal Chemistry, vol. 28, pp. 201-231, 1991.

[103] A. M. S. e Silva Beserra, P. I. Calegari, M. do Carmo Souza et al., "Gastroprotective and ulcer-healing mechanisms of ellagic acid in experimental rats," Journal of Agricultural and Food Chemistry, vol. 59, no. 13, pp. 6957-6965, 2011.

[104] S. Murakami, Y. Isobe, H. Kijima, H. Nagai, M. Muramatu, and S. Otomo, "Inhibition of gastric $\mathrm{H}^{+}, \mathrm{K}^{+}$-ATPase and acid secretion by ellagic acid," Planta Medica, vol. 57, no. 4, pp. 305-308, 1991.

[105] T. Iino, K. Tashima, M. Umeda et al., "Effect of ellagic acid on gastric damage induced in ischemic rat stomachs following ammonia or reperfusion," Life Sciences, vol. 70, no. 10, pp. 1139-1150, 2002.

[106] A. Muthuraman and S. Sood, "Antisecretory, antioxidative and antiapoptotic effects of montelukast on pyloric ligation and water immersion stress induced peptic ulcer in rat," Prostaglandins, Leukotrienes and Essential Fatty Acids, vol. 83, no. 1, pp. 55-60, 2010.

[107] N. S. Parmar and M. N. Ghosh, "Gastric anti-ulcer activity of (+)-cyanidanol-3, a histidine descarboxylase inhibitor," European Journal of Pharmacology, vol. 69, no. 1, pp. 25-32, 1981.

[108] C. L. F. de Almeida, S. A. Brito, T. I. de Santana et al., "Spondias purpurea L. (Anacardiaceae): antioxidant and antiulcer activities of the leaf hexane extract," Oxidative Medicine and Cellular Longevity, vol. 2017, Article ID 6593073, 14 pages, 2017.

[109] S. I. Chandranatath, S. M. A. Bastaki, and J. Singh, "Comparative study on the activity of lansoprazole, omeprazole and PD136450 on acidified ethanol- and indomethacin-induced gastric lesions in the rat," Clinical and Experimental Pharmacology and Physiology, vol. 29, no. 3, pp. 173-180, 2002.

[110] J. L. Mangan, "Nutritional effects of tannins in animal feeds," Nutrition Research Reviews, vol. 1, no. 1, pp. 209-231, 1988.

[111] K.-T. Chung, T. Y. Wong, C.-I. Wei, Y.-W. Huang, and Y. Lin, "Tannins and human health: a review," Critical Reviews in Food Science and Nutrition, vol. 38, no. 6, pp. 421-464, 1998.

[112] H. P. Parkman, J.-L. C. Urbain, L. C. Knight et al., "Effect of gastric acid suppressants on human gastric motility," Gut, vol. 42, no. 2, pp. 243-250, 1998.

[113] A. Singh, T. K. Bhat, and O. P. Sharma, "Clinical biochemistry of hepatotoxicity," Journal of Clinical Toxicology, vol. 4, p. 1, 2011.

[114] N. G. Baydar, G. Özkan, and O. Sağdiç, "Total phenolic contents and antibacterial activities of grape (Vitis vinifera L.) extracts," Food Control, vol. 15, no. 5, pp. 335-339, 2004.

[115] L. Tomás-Menor, A. Morales-Soto, E. Barrajón-Catalán, C. Roldán-Segura, A. Segura-Carretero, and V. Micol, "Correlation between the antibacterial activity and the composition of extracts derived from various Spanish Cistus species," Food and Chemical Toxicology, vol. 55, pp. 313322, 2013. 


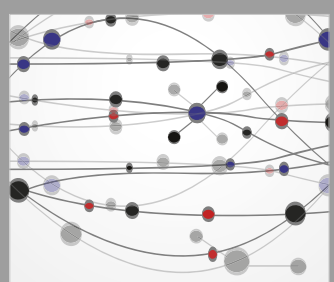

The Scientific World Journal
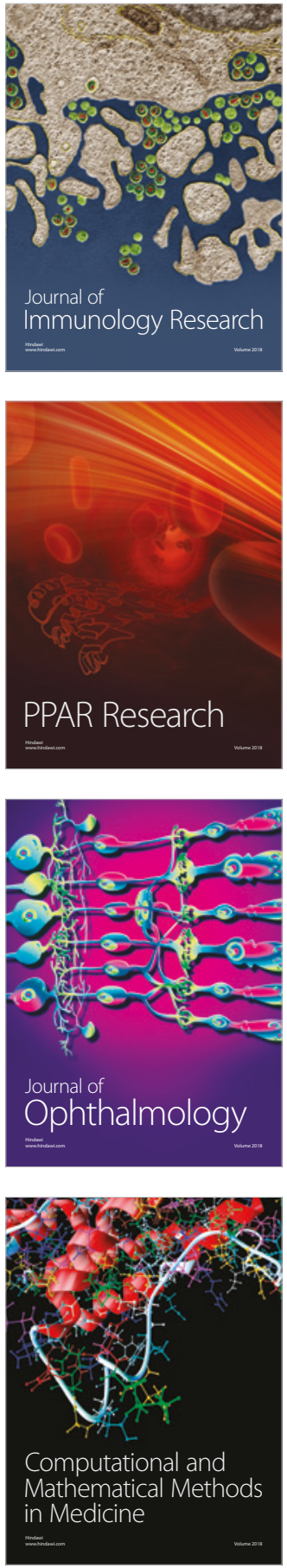

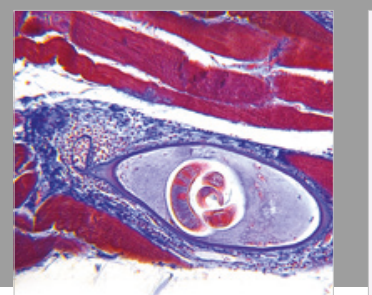

Gastroenterology Research and Practice

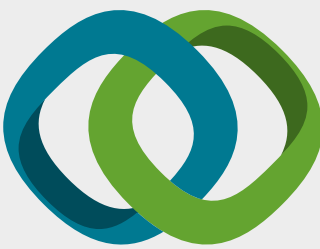

\section{Hindawi}

Submit your manuscripts at

www.hindawi.com
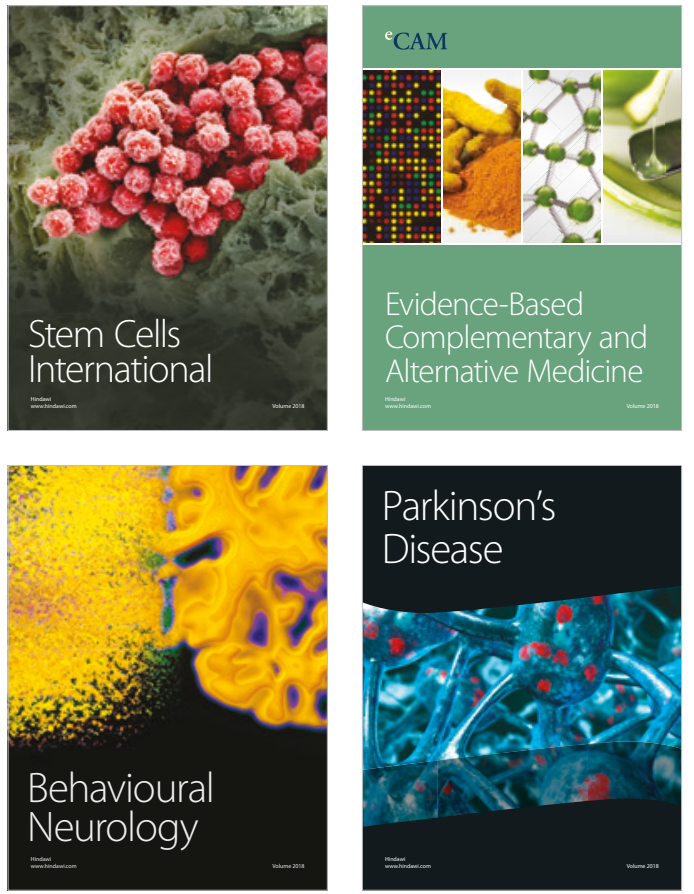

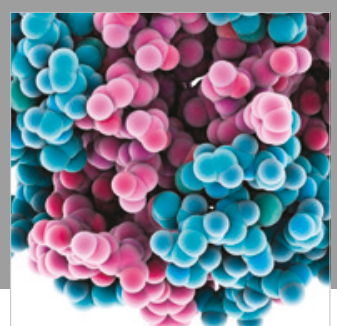

ournal of

Diabetes Research

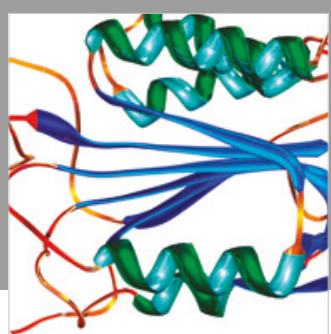

Disease Markers
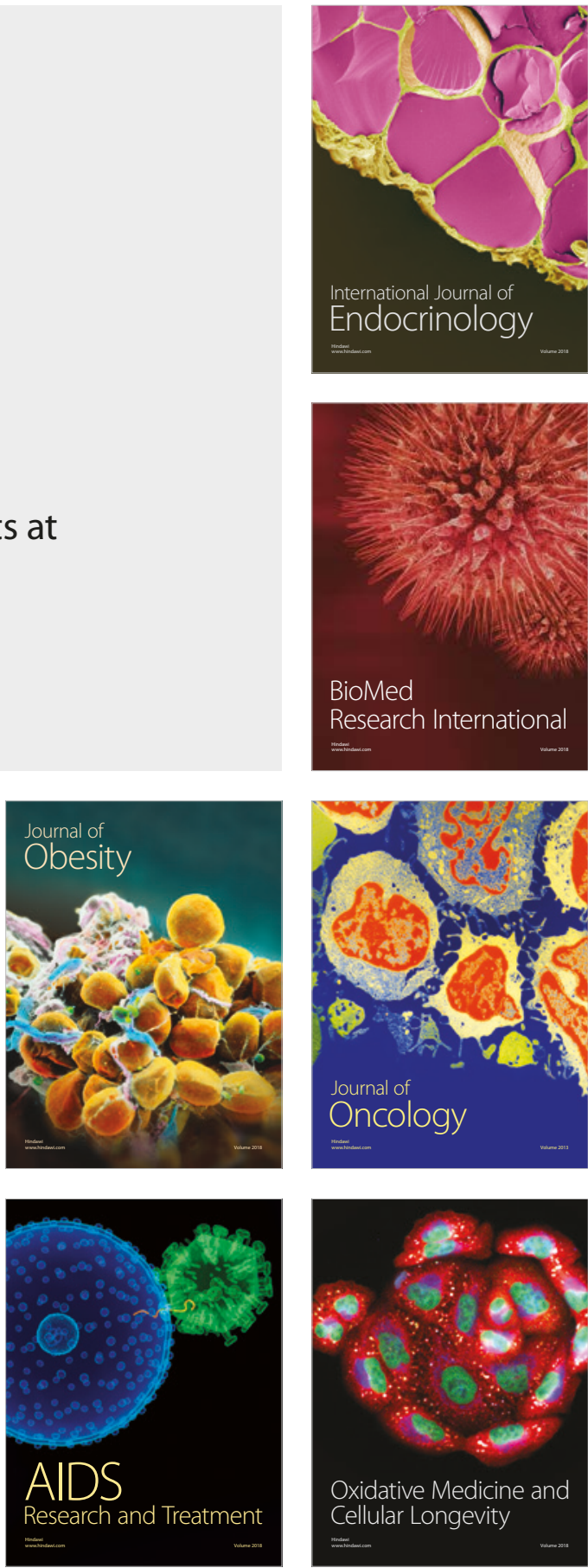